\title{
Human breast cancer cells generated by oncogenic transformation of primary mammary epithelial cells
}

\author{
Brian Elenbaas, ${ }^{1}$ Lisa Spirio, ${ }^{1}$ Frederick Koerner, ${ }^{2}$ Mark D. Fleming, ${ }^{3}$ Drazen B. Zimonjic, ${ }^{4}$ \\ Joana Liu Donaher, ${ }^{1}$ Nicholas C. Popescu, ${ }^{4}$ William C. Hahn, ${ }^{1,5}$ and Robert A. Weinberg ${ }^{1,6}$ \\ ${ }^{1}$ Whitehead Institute for Biomedical Research and Department of Biology, Massachusetts Institute of Technology, \\ Cambridge, Massachusetts 02142, USA; ${ }^{2}$ Department of Pathology, Massachusetts General Hospital and Harvard Medical \\ School, Boston, Massachusetts 02114, USA; ${ }^{3}$ Department of Pathology, Children's Hospital, Harvard Medical School, \\ Boston, Massachusetts 02115, USA; ${ }^{4}$ Laboratory of Experimental Carcinogenesis, National Cancer Institute, Bethesda, \\ Maryland 20892, USA; ${ }^{5}$ Department of Adult Oncology, Dana-Farber Cancer Institute, and Department of Medicine, \\ Brigham and Women's Hospital, Harvard Medical School, Boston, Massachusetts 02115, USA
}

\begin{abstract}
A number of genetic mutations have been identified in human breast cancers, yet the specific combinations of mutations required in concert to form breast carcinoma cells remain unknown. One approach to identifying the genetic and biochemical alterations required for this process involves the transformation of primary human mammary epithelial cells (HMECs) to carcinoma cells through the introduction of specific genes. Here we show that introduction of three genes encoding the SV40 large-T antigen, the telomerase catalytic subunit, and an H-Ras oncoprotein into primary HMECs results in cells that form tumors when transplanted subcutaneously or into the mammary glands of immunocompromised mice. The tumorigenicity of these transformed cells was dependent on the level of ras oncogene expression. Interestingly, transformation of HMECs but not two other human cell types was associated with amplifications of the c-myc oncogene, which occurred during the in vitro growth of the cells. Tumors derived from the transformed HMECs were poorly differentiated carcinomas that infiltrated through adjacent tissue. When these cells were injected subcutaneously, tumors formed in only half of the injections and with an average latency of 7.5 weeks. Mixing the epithelial tumor cells with Matrigel or primary human mammary fibroblasts substantially increased the efficiency of tumor formation and decreased the latency of tumor formation, demonstrating a significant influence of the stromal microenvironment on tumorigenicity. Thus, these observations establish an experimental system for elucidating both the genetic and cell biological requirements for the development of breast cancer.
\end{abstract}

[Key Words: Transformation; mammary; epithelial; ras; c-myc; fibroblast]

Received June 21, 2000; revised version accepted November 10, 2000.

Cancer arises from the aberrant growth of cells that have sustained mutations in genes controlling cell proliferation and survival. The great majority of human breast cancers arise from epithelial cells, and genetic analysis of tumor cells obtained from patients has revealed several commonly mutated genes. Mutations in the p53 tumor suppressor gene occur in over half of all tumors examined (Ozbun and Butel 1995). Breast cancers also frequently carry mutations that deregulate the retinoblastoma protein $(\mathrm{pRB})$ pathway including loss of expression of pRB or p16 $6^{\mathrm{INK} 4 a}$ (Varley et al. 1989; Brenner et al. 1996) or amplification or overexpression of cyclin D1 (Gillett et al. 1994). Breast carcinoma cells also com-

${ }^{6}$ Corresponding author.

E-MAIL weinberg@wi.mit.edu; FAX (617) 258-5213.

Article and publication are at www.genesdev.org/cgi/doi/10.1101/ gad.828901. monly acquire alterations in the Ras-signaling pathway (Clark and Der 1995), which may occur by several mechanisms, most notably amplification or overexpression of the HER-2/neu gene (Slamon et al. 1989). C-myc is also frequently amplified or overexpressed (Escot et al. 1986). Whereas these individual genetic mutations have been cataloged in numerous breast cancers, none is involved universally in all human breast cancers, and the number of mutant genes that coexist in the genome of a naturally arising breast cancer cell is unknown. As a consequence, it has been impossible to know how many mutant genes are required to convert a normal human mammary epithelial cell (HMEC) into a tumor cell.

One approach to this problem has involved the introduction of mutant cancer-associated genes into immortalized HMEC cell lines. Although this has led to the creation of tumorigenic derivative lines, the genetic na- 
ture of the resulting cell lines has been impossible to resolve, because the immortalized cell lines were of unknown genetic constitution due to the experimental strategies used previously to immortalize them. Such strategies have included treatment of HMECs with chemicals such as benzo(a)pyrene or selection of immortalized cell clones following extended passage in culture (for review, see Ethier 1996). For this reason, it is impossible to know how a particular introduced gene interacts functionally with the existing mutant alleles in these immortalized cells to create resulting phenotypes.

We sought to develop an in vitro system for the transformation of primary HMECs into a tumorigenic state to begin to define the genetic changes required in concert to give rise to a breast carcinoma cell. Although primary rodent cells are easily transformed by two concomitantly introduced oncogenes (Land et al. 1983; Ruley 1983), only recently have primary human cells been transformed by a similar strategy (Hahn et al. 1999). In this more recent work, two types of normal human cells, human embryonic kidney cells (HEK) and foreskin fibroblasts (BJ), were transformed by introducing a genomic version of the SV40 large-T (LT) oncogene, the hTERT gene that encodes the telomerase catalytic subunit, and an oncogenic allele of the H-ras gene, H-rasV12. This suggested that a limited set of growth-deregulating changes, each evoked by a distinct genetic element, is required for tumorigenic conversion of these two types of human cells. These changes minimally involved the inactivation of the p53 and pRB pathways (achieved in this instance by LT), telomere maintenance conferred by hTERT, and acquisition of a constitutive mitogenic signal provided by oncogenic H-ras. Furthermore, this work showed that the transformation of human cells into tumor cells operates on different principles from those governing rodent cell transformation. As such, many of the lessons drawn from study of the transformation of mouse cells may need to be revisited when studying human cells.

We sought to extend these initial human cell transformation experiments by using HMECs to examine the mechanisms governing their tumorigenic conversion. Like other human cell types, HMECs exhibit a limited replicative lifespan in culture. The proliferation of HMECs isolated from reduction mammoplasties and propagated in a defined, serum-free mammary epithelial growth medium (MEGM) is limited to $\sim 15$ population doublings (PD) in culture due to a growth arrest termed M0 (Stampfer 1985; Foster and Galloway 1996). This initial block can be overcome by ectopic expression of the human papillomavirus (HPV) E7 oncogene or by spontaneous loss of $\mathrm{p} 16^{\mathrm{INK} 4 \mathrm{a}}$ gene expression, implicating the pRB pathway in this initial growth arrest (Foster and Galloway 1996; Foster et al. 1998). In the subpopulation of cells that bypass M0 through the loss of $\mathrm{p} 16^{\mathrm{INK} 4 \mathrm{a}}$ expression, ectopic expression of the HPV E6 oncoprotein, which inactivates the p53 tumor suppressor protein, enables bypass of the subsequently observed senescence (M1) (Band et al. 1991; Shay et al. 1993). However, HMECs that have lost $\mathrm{p} 16^{\mathrm{INK} 4 \mathrm{a}}$ expression and express
E6 eventually progress to a state termed crisis (M2), which is characterized by critically short telomeres and cell death (Shay et al. 1993).

The introduction of hTERT into HMECs that have bypassed M0 due to loss of $\mathrm{p} 16^{\mathrm{INK} 4 \mathrm{a}}$ expression has been reported to enable these cells to bypass both $\mathrm{M} 1$ and M2 and achieve immortalization (Kiyono et al. 1998). This dual requirement of loss of $\mathrm{p} 16^{\mathrm{INK} 4 \mathrm{a}}$ expression and hTERT expression for immortalization in culture is similar to that observed in human keratinocytes (Kiyono et al. 1998). However, the process of immortalization is, on its own, insufficient to create a fully transformed, tumorigenic cell (Hahn et al. 1999; Jiang et al. 1999; Morales et al. 1999), which requires the additional introduction of an oncogene such as ras (Hahn et al. 1999).

Whereas these or analogously acting genetic changes appear to be required to create tumorigenic cells, their actions within such cells still do not explain the full biological complexity of tumorigenesis. Tumors are complex mixtures of a variety of distinct cell types, including endothelial cells, inflammatory cells, and fibroblasts that are believed to aid the proliferation of the malignant cells. Breast carcinomas, like other epithelium-derived tumors, often contain a large stromal component composed of specialized fibroblasts, referred to as activated fibroblasts. These activated fibroblasts can be contrasted with their counterparts in the normal breast by their increased proliferation, altered extracellular matrix, ability to promote neovascularization, and expression of myofibroblast markers (Ronnov-Jessen et al. 1996). It has been proposed that these fibroblasts actively contribute to tumor formation in a way that remains poorly understood (Ronnov-Jessen et al. 1996; Rowley 1998). For these reasons, we have created a series of transformed HMECs and investigated the influence of both genetic and cell biological factors on their tumorigenicity.

\section{Results}

Conversion of primary HMECs into tumorigenic breast epithelial cells

The HMECs used in our initial studies were derived from a reduction mammoplasty tissue sample from a woman without known breast pathology. These cells (passage 7, PD 23, Clonetics) were propagated in MEGM and uniformly expressed E-cadherin and the epithelial cytokeratins 14 and 18 as revealed by immunofluorescence staining, indicating that they were of epithelial origin (data not shown). The coexpression of these two cytokeratins, which are expressed by distinct epithelial cell types in the normal gland (cytokeratin 14 in basal cells and cytokeratin 18 in luminal cells), may indicate that these HMECs have bipotential or multipotential mammary epithelial stem cell characteristics (Bartek et al. 1985; Ethier 1996). These cells did not express $\alpha$-smooth muscle actin by immunofluorescence, indicating that they were not myoepithelial cells (data not shown). 
In accord with previous observations (Foster et al. 1998), we found that these HMECs lack expression of p16 ${ }^{\mathrm{INK} 4 \mathrm{a}}$ protein by immunoblot analysis, as they had already bypassed the initial M0 growth arrest in culture (data not shown). These cells also lack expression of the estrogen receptor (ER) and therefore provide the opportunity to model the development of ER-negative breast cancers, which comprise approximately one-third of all breast cancers, are typically more poorly differentiated, and have a poorer clinical outcome than those expressing the ER (Lapidus et al. 1998). The HMECs were infected successively with replication-defective amphotropic retroviruses generated from Moloney-based expression constructs, each encoding a distinct drug selection marker. Following each infection, polyclonal populations were selected by drug resistance; typically $20 \%-40 \%$ of the HMECs were successfully infected during each cycle. For each infection, a parallel culture of cells was infected with a control retrovirus expressing only a drug resistance marker gene. The tumorigenicity of various resulting populations of HMECs was determined by their abilities to form tumors when injected subcutaneously into nude mice and to form colonies in soft agar, a measure of anchorage-independent growth that typically correlates with tumorigenicity.

Initially, we tested whether immortalization of HMECs by the spontaneous loss of $\mathrm{p} 16^{\text {INK4a }}$ and expression of hTERT cooperated with expression of the $\mathrm{H}-\mathrm{ras} \mathrm{V} 12$ oncogene to achieve transformation. HMECs were infected with retrovirus generated from the pBabehygro $h T E R T$ vector followed by infection with retrovirus generated from the pBabe-puro H-rasV12 vector.
Confirming earlier observations (Kiyono et al. 1988), the introduction of $h T E R T$ enabled these HMECs to bypass senescence and become immortal (data not shown). The subsequent expression of $\mathrm{H}$-rasV12 did not result in a senescence growth arrest, as observed with several other human cell types (Serrano et al. 1997). However, HMECs expressing hTERT alone or the combination of hTERT and $\mathrm{H}$-rasV12 failed to form colonies when grown in soft agar (Fig. 1B) and to form tumors in nude mice (Table 1). Thus, deregulation of the pRB pathway through the loss of $\mathrm{p} 16^{\mathrm{INK} 4 \mathrm{a}}$ expression in combination with expression of hTERT and H-rasV12 was not sufficient for transformation.

Because LT was found to be necessary for the transformation of two other types of human cells (Hahn et al. 1999|, this suggested that inactivation of the p53 tumor suppressor, which is achieved by LT, might also be required for the transformation of HMECs. Thus, we attempted to transform HMECs with combinations of LT, hTERT, and H-rasV12. To express LT in HMECs, we used the same retroviral vector that we used previously in the transformation of HEK and BJ fibroblasts (Hahn et al. 1999). This vector transduces the genomic sequence of the SV40 early region (Jat et al. 1986) and encodes both the LT and small $\mathrm{t}$ antigens. HMECs (PD23) were infected with this LT retroviral vector followed by infection with a vector encoding either H-rasV12 or hTERT. HMECs expressing LT alone or the combination of LT and H-rasV12 grew past senescence (M1) at PD39 but eventually encountered crisis (M2) at PD57 (Fig. 1A). HMECs expressing LT or the combination of LT and $\mathrm{H}$-rasV12 failed to form colonies in soft agar (Fig. 1B) and
Figure 1. In vitro growth and anchorage-independent growth of the HMECs expressing various combinations of $\mathrm{LT}, \mathrm{hTERT}$, and $\mathrm{H}$ rasV12. (A) Growth curves of Clonetics HMECs (PD23) ( $\bullet$, HMECs expressing LT (घ), or HMECs expressing both LT and hTERT ( $)$. The expression of LT enables HMECs to bypass senescence (M1) at PD39. The additional expression of $h T E R T$ enables the cells to bypass crisis (M2) at PD57. (B) HMECs were generated with the indicated combinations of LT, hTERT, and H-rasV12. The level of overexpression of $\mathrm{H}$-ras $\mathrm{V} 12$ protein in the indicated populations of cells is compared by immunoblot analysis for H-Ras. The number of soft agar colonies is indicated for $5 \times 10^{4}$ cells. Results are expressed as the mean of three experiments +/- S.D. (C) Growth curves of the second population of HMECs, termed PHMECs $(\bullet)$, PHMECs expressing LT (घ), or PHMECs expressing both LT and hTERT (৩). (D) Immunoblot analysis of p16 $6^{\mathrm{INK} 4 \mathrm{a}}$ in $293 \mathrm{~T}$ cells and the two populations of HMECs, each expressing LT, hTERT, and H-rasV12 (HMLER and PHMLER).

A
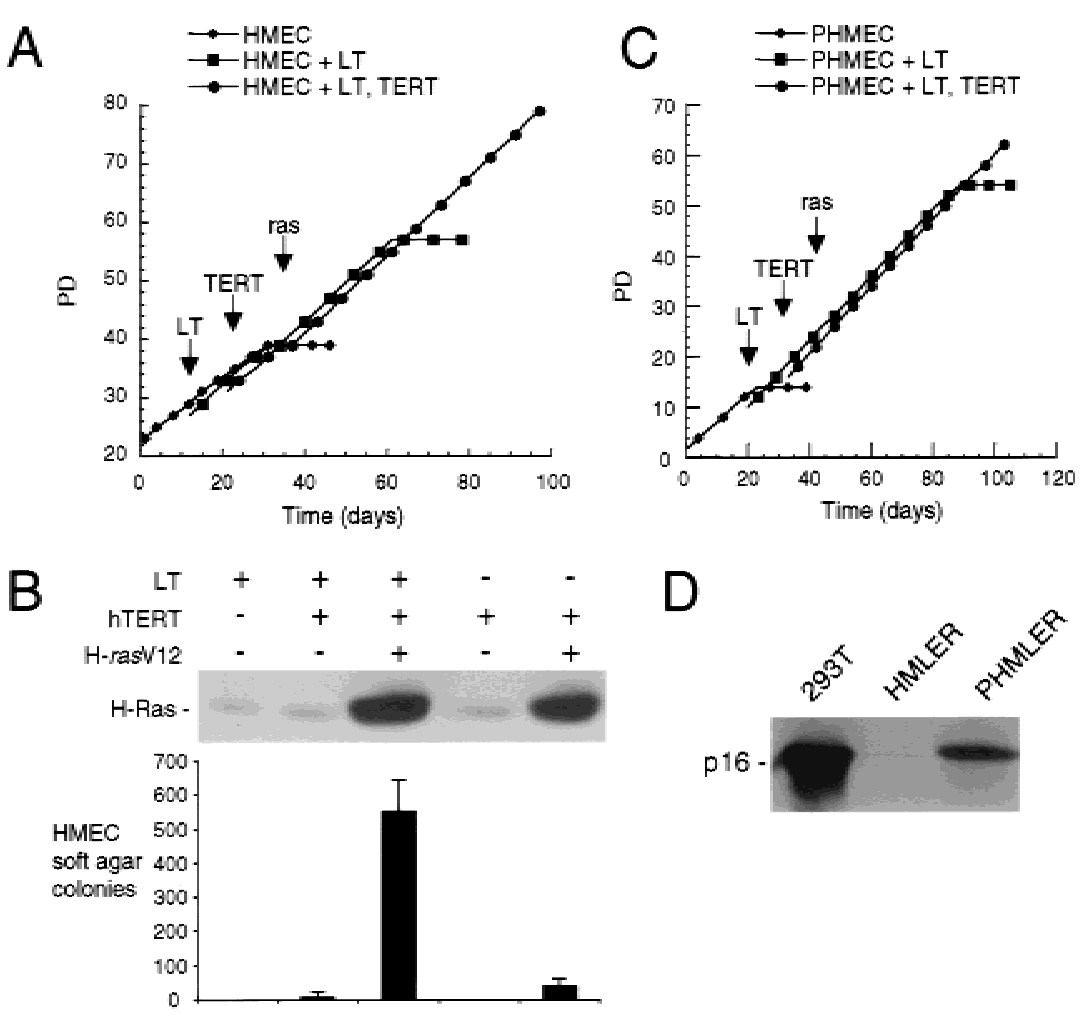
Table 1. Formation of subcutaneous tumors in nude mice

\begin{tabular}{llcc}
\hline Cells & \multicolumn{1}{c}{ Genotype } & $\begin{array}{c}\text { No. tumors/ } \\
\text { injection }\end{array}$ & $\begin{array}{c}\text { Ras } \\
\text { over- } \\
\text { expression }\end{array}$ \\
\hline HMEC & hTERT, V & $0 / 3$ & - \\
& hTERT, Ras-puro & $0 / 6$ & 12.0 \\
& LT, V, V & $0 / 3$ & - \\
& LT, hTERT, V & $0 / 6$ & - \\
& LT, Ras-puro & $0 / 3$ & 12.0 \\
& LT, hTERT, Ras-hygro & $0 / 24$ & 3.5 \\
& LT, hTERT, Ras-zeo & $1 / 15$ & 7.2 \\
PHMEC & LT, hTERT, Ras-puro & $14 / 27$ & 12.0 \\
HEK & LT, hTERT, Ras-puro & $0 / 9$ & 0 \\
& LT, hTERT, Ras-hygro & $6 / 9$ & 14.0 \\
& LT, hTERT, Ras-puro & $15 / 7$ & 9.5 \\
\hline
\end{tabular}

For each injection, $2 \times 10^{6}$ cells of the indicated populations were injected subcutaneously in a volume of $200 \mu \mathrm{L}$. Ras-puro indicates an infection with retrovirus generated from the pBabepuro H-rasV12 construct, Ras-hygro from pBabe-hygro H-rasV12, and Ras-zeo from pBabe-zeo H-rasV12. A control pBabe vector infection is indicated by $\mathrm{V}$. Ras overexpression indicates the fold overexpression of the introduced H-ras V12 protein in comparison to the endogenous H-Ras. Tumor formation was scored as negative after 3 mo of monitoring.

failed to form tumors in nude mice (Table 1). In contrast, cells expressing both LT and hTERT continued to grow past crisis (Fig. 1A) and were immortalized. However, these immortalized HMECs failed to form colonies in soft agar (Fig. 1B) and tumors in nude mice (Table 1).

Because the pairs of genes described above failed to cause transformation, we tested whether the triple combination of LT, hTERT, and H-rasV12 could cause transformation. HMECs expressing LT and hTERT were infected with a retrovirus encoding H-rasV12. Generation of these cells from PD 23 HMECs (termed HMLER) took $43 \mathrm{~d}$ with the cells undergoing a total of $\sim 24 \mathrm{PD}$ during this period (Fig. 1A). These HMLER cells formed colonies in soft agar (Fig. 1B) and formed tumors with an efficiency of $52 \%$ (14/27) of injections (Table 1). HMLER cells expressed similar levels of the LT protein as the previously reported HEK and BJ fibroblast cells transformed with the same three genes (Fig. 2A) (Hahn et al. 1999). These various cells expressed comparable levels of hTERT mRNA, as assessed by RT-PCR analysis, and expressed similar levels of telomerase activity, as measured by the telomeric repeat amplification protocol (TRAP) assay (Fig. 2B). HMLER cells expressed 12-fold more ectopic H-RasV12 protein than endogenous H-Ras (Fig. 2A). Hence, the combination of LT, hTERT, and $\mathrm{H}$-rasV12 is capable of tumorigenic transformation the HMECs as it was in the previously studied HEK cells and BJ fibroblasts.

The initial population of HMECs (Clonetics) used in these transformation studies had bypassed M0 and had lost $\mathrm{p} 16^{\mathrm{INK} 4 \mathrm{a}}$ expression prior to manipulation by us. To exclude the possibility that changes occurred during the establishment of these cells prior to our manipulations, we isolated a population of HMECs (termed PHMECs) directly from a reduction mammoplasty tissue sample for similar transformation studies. This second population was isolated and grown as described (Stampfer 1985) and expressed the same set of markers as the HMECs analyzed previously (data not shown).

These PHMEC cells were infected with the LT-expressing retrovirus very early following their isolation (PD10) prior to their encountering M0. We subsequently confirmed that this introduction of LT and the resulting functional inactivation of $\mathrm{pRB}$ obviated the spontaneous inactivation of $\mathrm{p} 16^{\mathrm{INK} 4 \mathrm{a}}$ expression by these cells as gauged by immunoblot analysis (Fig. 1D). Thus, similar to the introduction of the HPV E7 protein (Foster and Galloway 1996), expression of the LT oncoprotein into HMECs early in their passaging history renders the spontaneous inactivation of their $\mathrm{p} 16^{\mathrm{INK} 4 \mathrm{a}}$ gene unnecessary.

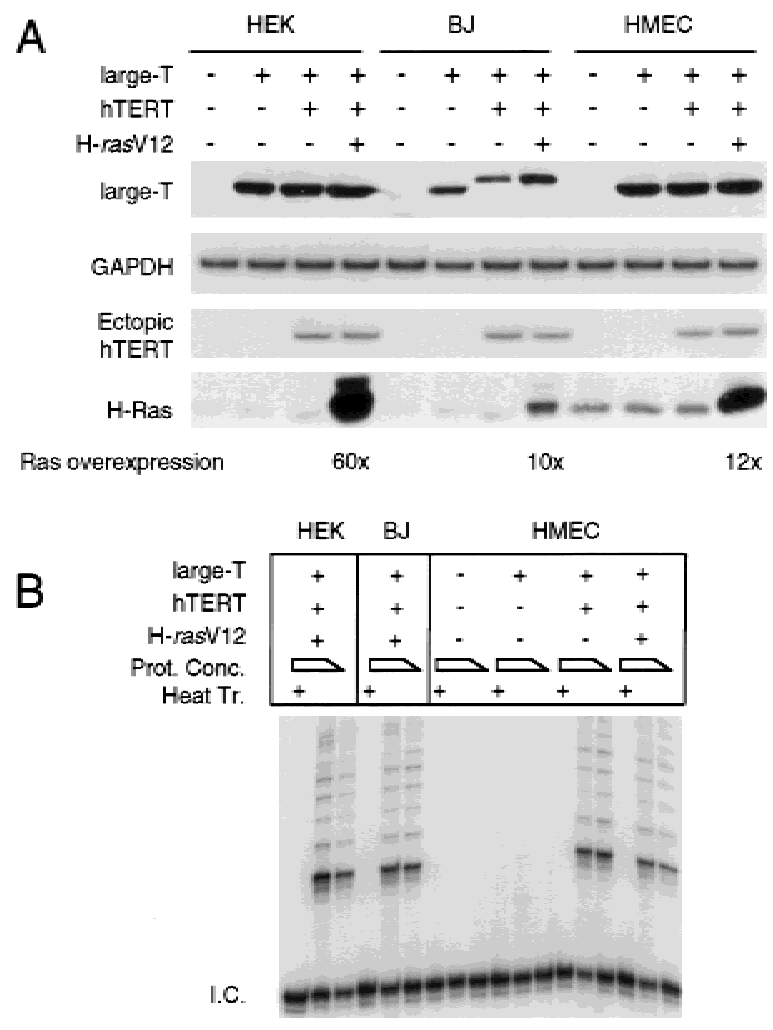

Figure 2. Comparison of the expression levels of LT, hTERT. and H-rasV12 in the HEK cells, BJ fibroblasts, and HMECs. (A) Immunoblot analysis demonstrates that the levels of LT in the HMECs are similar to those in the HEK and BJ cells. RT-PCR for ectopic hTERT mRNA shows that hTERT is expressed at similar levels in the three cell populations. The level of GAPDH mRNA in each sample was measured as an internal control for the RT-PCR. Immunoblot analysis of H-Ras shows a 12-fold overexpression of H-rasV12 in the HMECs, a 60-fold overexpression in the HEK cells, and a 10-fold overexpression in the BJ fibroblasts. (B) Telomerase activity as measured by the TRAP assay was compared in indicated cell populations. For each sample, a heat-treated control reaction with $200 \mathrm{ng}$ of protein was performed followed by reactions with $200 \mathrm{ng}$ and $50 \mathrm{ng}$ of protein. The internal PCR control (IC) is indicated at the bottom. 
The subsequent addition of hTERT and H-rasV12 into this population of PHMEC cells resulted in cells that formed tumors with an efficiency comparable with that observed with the HMLER cells studied previously (6/9 injections, Table 1) and with a similar latency (data not shown). PHMECs expressing the combination of LT and hTERT failed to form tumors in nude mice (Table 1). Both the HMECs and PHMECs expressing LT, hTERT, and $\mathrm{H}$-rasV12 grew at a similar rate in vitro and formed a similar number of colonies when grown in soft agar (data not shown). The process of introducing the three genes into the PHMECs required a similar amount of time and total number of PD (40 days, $22 \mathrm{PD}$ ) as the initially used HMEC population. Thus, transformation of HMECs by introduction of the LT, hTERT, and $\mathrm{H}$ ras V12 genes is independent of loss of $\mathrm{p} 16^{\mathrm{INK} 4 \mathrm{a}}$ expression specifically, and we conclude that the transformation protocol used with these two populations of HMECs is likely to succeed with all primary mammary epithelial cells.

\section{Requirement for high-level oncogenic Ras expression} for transformation

During the process of generating the HMLER cells, we determined that these cells, as well as the HEK and BJ cells transformed with the same set of three genes, expressed a high level of the $\mathrm{H}$-ras V12 protein when compared with endogenously expressed wild-type H-Ras protein (Fig. 2A). Specifically, the level of H-Ras overexpression was 12-fold in the HMECs, 10-fold in the BJ cells, and 60 -fold in the HEK cells. To test whether a specific threshold level of H-rasV12 expression was required for transformation, we generated two additional populations of HMLER cells that expressed lower levels of H-rasV12. We did so by expressing H-rasV12 from two other retroviral expression constructs, pBabe-hygro and pBabe-zeo, which we found to induce lower levels of Ras expression than the initially used pBabe-puro vector.

Analysis of these three populations of cells confirmed that they expressed significantly different levels of $\mathrm{H}$ Ras protein. HMLER cells infected with pBabe-hygro $\mathrm{H}$ ras V12 expressed the lowest level of oncogenic Ras (3.5fold above the endogenous Ras level), cells with pBabezeo H-rasV12 expressed intermediate levels (7.2-fold), and cells with pBabe-puro H-rasV12 expressed the highest level of Ras (12-fold) (Fig. 3). When the respective abilities of the three populations of HMLER cells to form colonies in soft agar were compared, a close correlation with the level of H-rasV12 was observed (Fig. 3). Furthermore, the tumorigenicity of the three populations of cells correlated with the level of overexpression of $\mathrm{H}$ rasV12. HMLER cells with a low level of H-rasV12 expression from the pBabe-hygro construct failed to form tumors when injected subcutaneously (0/24 injections) (Table 1). Cells with an intermediate level of H-rasV12 expressed from the pBabe-zeo construct rarely formed tumors $(11 \%, 1 / 15$ injections $)$ and cells with high-level $\mathrm{H}$-rasV12 expressed from the pBabe-puro construct

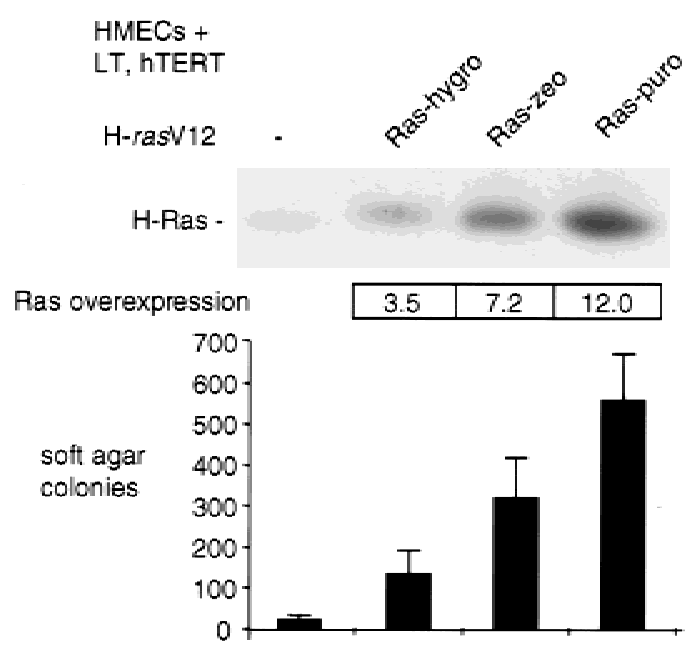

Figure 3. Anchorage-independent growth of the HMECs expressing LT, hTERT, and different levels of H-rasV12. The level of overexpression of $\mathrm{H}$-ras V12 is compared by immunoblot analysis with an antibody specific for $\mathrm{H}$-Ras in the indicated cells. Three different populations of HMECs expressing different levels of H-rasV12 were generated by infection of HMECs expressing LT and hTERT with retrovirus generated from pBabe-hygro H-rasV12 (Ras-hygro), pBabe-zeo H-rasV12 (Raszeo), and pBabe-puro H-rasV12 (Ras-puro). The number of soft agar colonies is indicated for $5 \times 10^{4}$ cells. Results are expressed as the mean of three experiments +/- S.D.

formed tumors $52 \%$ of the time (14/27 injections). Hence, expression of H-rasV12 above a critical threshold level is required for tumorigenic transformation of HMECs in the presence of the coexpressed LT and hTERT genes.

These experiments raised the question of whether this observed requirement for high-level oncogenic Ras expression was specific to HMECs or was instead a more general phenomenon associated with the transformation of other cell types. To test this notion, we expressed the ras oncogene at relatively low levels in HEK cells, in contrast to previous experiments in which the Ras protein was expressed at high levels and succeeded in transforming the cells to a tumorigenic state (Hahn et al. 1999). Thus, HEK cells expressing LT and hTERT were infected with retrovirus generated from the pBabe-hygro $\mathrm{H}$-rasV12 vector to express lower levels of H-rasV12. These cells expressed a much lower level of H-rasV12 (9.5-fold overexpression) when compared with the pBabe-puro H-rasV12 infected cells that expressed a substantially higher level of H-rasV12 (60-fold) (Fig. 4). Similar to the results obtained with the HMECs, HEK cells expressing LT, hTERT, and low-level H-rasV12 formed very few colonies in soft agar (Fig. 4) and rarely formed tumors in nude mice (1/7 injections) (Table 1$)$. The one tumor that formed did so after a latency of $6 \mathrm{wk}$ in comparison with tumors from the high-level Ras expressing cells that formed after $\sim 2$ wk (Fig. 6A, below). HEK cells with LT, hTERT, and high-level H-rasV12 formed many colonies in soft agar and consistently formed tumors in nude mice (15/15 injections). We conclude that transfor- 

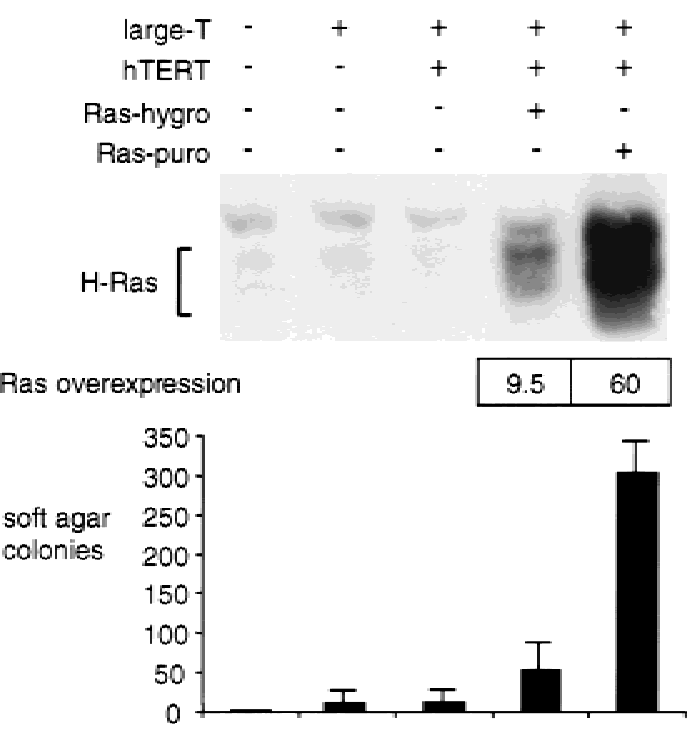

Figure 4. Anchorage-independent growth of HEK cells expressing LT, hTERT, and different levels of $\mathrm{H}$-rasV12. Two populations of HEK cells expressing different levels of H-rasV12 were generated by infection of HEK cells expressing LT and hTERT with retrovirus generated from pBabe-hygro H-rasV12 (Ras-hygro) and pBabe-puro H-rasV12 (Ras-puro). The level of overexpression of $\mathrm{H}$-ras V12 is compared by immunoblot analysis with an anti-H-Ras antibody. The number of soft agar colonies is indicated for $5 \times 10^{3}$ cells. Results are expressed as the mean of three experiments $+/-$ S.D.

mation of both HMECs and HEK cells by LT, hTERT, and $\mathrm{H}$-ras V12 requires levels of the Ras oncoprotein that are expressed at least 10 -fold above the endogenous level of wild-type $\mathrm{H}$-Ras protein in these cells.

\section{Histological analysis of subcutaneous and orthotopic tumors derived from the transformed HMECs}

Hematoxylin and eosin staining of the subcutaneous tumors revealed that they were poorly differentiated carcinomas (Fig. 5A). The tumors had large, pleomorphic nuclei, prominent nucleoli, and several mitotic figures per high-powered field. Immunoperoxidase staining with the cytokeratin antibody AE1/AE3 showed strong staining throughout the tumor, validating the epithelial nature of the tumor (Fig. 5B). These tumors did not express ER by immunoperoxidase staining as expected, because the initial population of unmanipulated HMECs did not express ER (data not shown). Immunoperoxidase staining also showed that the tumors lacked expression of $\alpha$-smooth muscle actin, reinforcing the notion that this population of HMECs does not represent cells of the myoepithelial lineage.

Approximately one-half of the tumors had small regions of squamous differentiation distinguished by the formation of keratin pearls and intercellular bridges (Fig. 5C). Stromal fibroblasts present in these tumor masses were readily distinguished in the hematoxylin and eosin

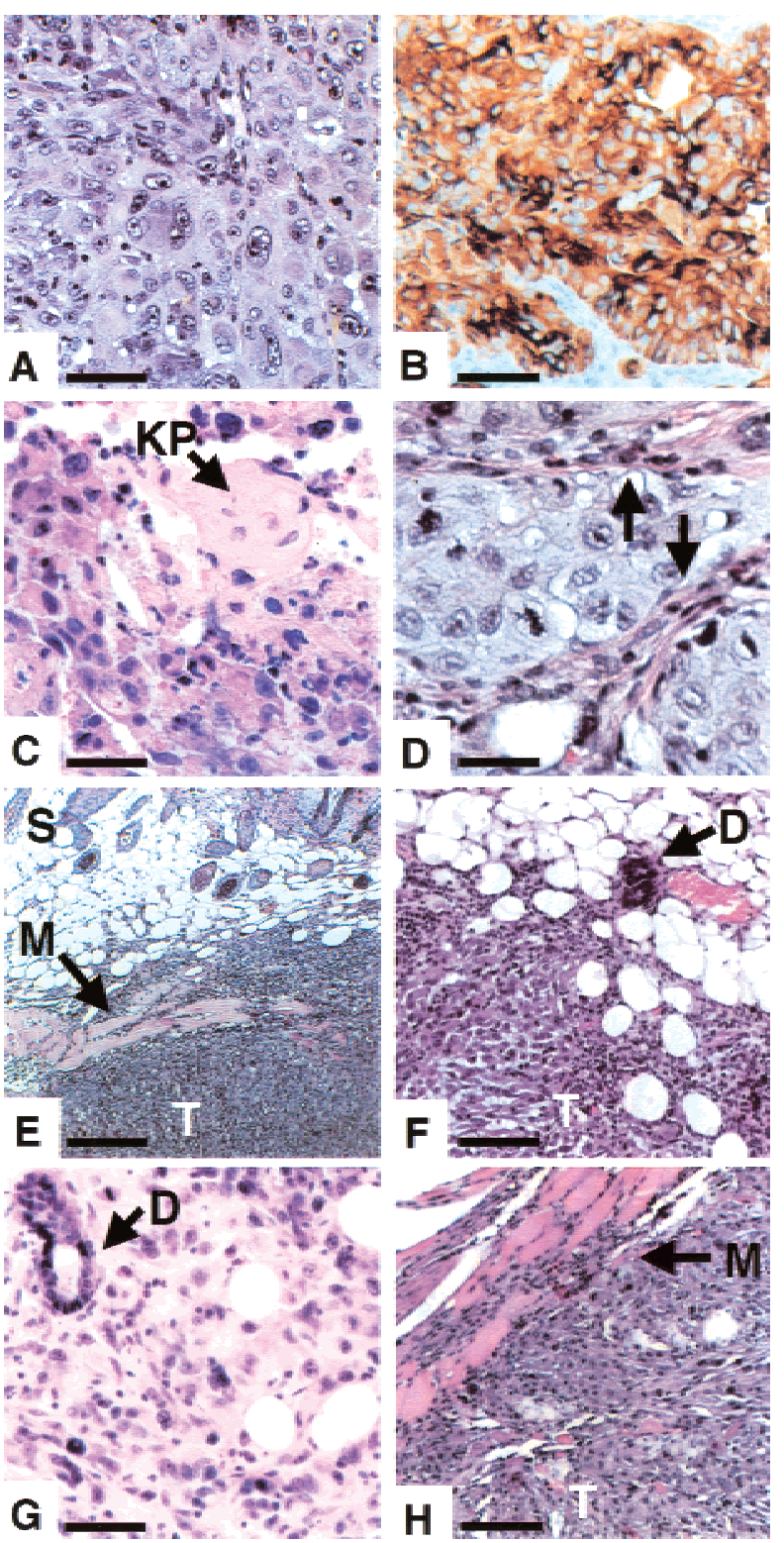

Figure 5. Histology of subcutaneous and orthotopic tumors derived from HMLER cells with high-level expression of $\mathrm{H}$-rasV12. All panels were stained with hematoxylin and eosin with the exception of $B .(A, B, C, E)$ Subcutaneous tumors; $(D, F, G, H)$ mammary gland tumors. (A) The tumors were poorly differentiated with large pleomorphic nuclei and prominent nucleoli. (B) Immunoperoxidase staining with the cytokeratin antibody AE1/AE3 shows the epithelial nature of the tumor. $(C)$ A subset of the tumors had regions of squamous differentiation and keratin pearls $(\mathrm{KP})$. (D) A close intermingling of epithelial tumor cells and stromal fibroblasts (indicated by the arrows) was observed. The epithelial cells are the larger, paler staining cells and the fibroblasts are the smaller, elongated, pinker staining cells. A white $\mathrm{T}$ indicates tumor in $E, F$, and $H$. $(E)$ Subcutaneous tumors showed infiltration through the thin layer of muscle (M) and the adipose tissue just beneath the skin $(S) .(F, G)$ Tumors that grew in the mammary glands infiltrated through adipocytes and around ducts (D). (H) One of the five mammary gland tumors showed infiltration into the abdominal muscle. Bars, $75 \mu \mathrm{m}$ in $A, C, D, G ; 200 \mu \mathrm{m}$ in $B, F, H ; 400 \mu \mathrm{m}$ in $E$. 
sections by their elongated morphology, normal nuclei, and pink-staining collagen deposition in the surrounding matrix. Mouse stromal fibroblasts were closely intermingled with the epithelial tumor cells throughout the tumors, suggesting an active participation of these normal fibroblasts in tumor formation (Fig. 5D).

Evidence from a variety of sources indicates that tumor biology is not governed exclusively by cell-autonomous processes (Miller et al. 1981; Fidler et al. 1990; Price et al. 1990; Olumi et al. 1999|, suggesting that the microenvironment of the tumor cell exerts strong influence on tumor cell phenotype and, in turn, on the development of the tumor mass as a whole. Tumor cells may behave quite differently when introduced into different sites within a host mouse. Certain mouse mammary tumor lines (Miller et al. 1981) and human breast tumor lines (Price et al. 1990) exhibit higher rates of tumor formation when injected into an orthotopic site (i.e., the mouse mammary gland) than into a subcutaneous site.

To examine the influence of tissue microenvironment on tumor formation by the HMLER cells, we introduced these cells into intact mammary glands of immunocompromised $R A G 1^{-/-}$mice. Following injection, mice were sacrificed upon observation of tumors $1 \mathrm{~cm}$ in diameter or after 10 weeks with no observable tumor. Similar to the results observed following subcutaneous injections, only populations of HMLER cells expressing a high-level of H-rasV12 succeeded in forming tumors. However, the efficiency of tumor formation was poor, with tumors arising in only $13 \%(5 / 38)$ of injections. HMLER cells expressing low-level H-rasV12 failed to form tumors after 25 injections. Control injections of the highly tumorigenic human breast cancer cell line MDA-MB-435 formed tumors in 10/10 injections. To address the possibility that the poor tumor formation observed in the mammary gland was due to differences between the biology of the two mouse strains used in these experiments, we injected HMLER cells subcutaneously into $R A G 1^{-1-}$ mice. Tumors formed in 56\% (5/9) of injections in the $R A G 1^{-/-}$mice as compared with $52 \%(14 / 27)$ in the nude mice, and the tumors formed with a similar latency (data not shown), indicating that strain differences did not influence tumorigenicity. Therefore, contrary to our initial expectations, tumor formation was less efficient in the mammary gland than in the subcutaneous site.

Both the subcutaneous tumors and those in the mammary fat pad had invasive characteristics, as they infiltrated through several types of adjacent tissue. The subcutaneous tumors spread through the thin layer of skeletal muscle and the adipose tissue just beneath the skin (Fig. 5E). Tumors that arose from mammary gland injections infiltrated throughout the gland, spreading through adipocyte layers and migrating around ducts (Fig. 5F,G). One mammary gland tumor also showed infiltration into the skeletal muscle of the abdominal wall (Fig. 5H). No signs of metastatic spread were observed in several of the tumor-bearing mice either by gross inspection of the mice or by hematoxylin and eosin staining of sections of the lung, liver, spleen, and kidney.
Effects of Matrigel and mammary fibroblasts on the tumorigenicity of HMLER cells

The transformed HMEC cells described here differed significantly from the HEK (kidney) and BJ (fibroblast) transformants in the efficiency of tumor formation and the latency with which they formed palpable tumors following subcutaneous implantation in nude mice. The HEK and BJ cells expressing the combination of LT, hTERT, and H-rasV12 formed tumors in $100 \%$ of injections, whereas the HMLER cells, even those expressing high-level H-rasV12, formed tumors in only $52 \%$ of injections (Table 1). The transformed HEK and BJ cells also formed tumors rapidly, achieving a diameter of $9 \mathrm{~mm}$ within 3 weeks (Fig. 6A). In stark contrast, the HMECs carrying the same three genes expressed at comparable levels formed tumors that were first apparent at an average of 52 days $(n=14)$ after implantation. These HMEC-derived tumors subsequently grew at a slower rate than did the HEK and BJ-derived tumors. The long latency and inefficient growth of these transformed HMECs mimic the growth of many breast cancer cell lines derived from patients in immunodeficient animals.

Others have reported that altering the tumor microen-
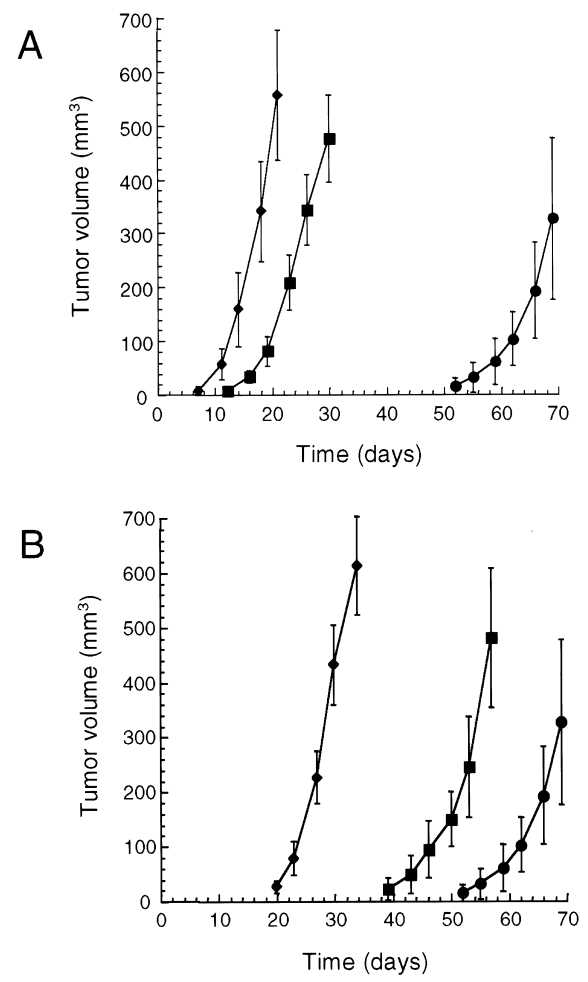

Figure 6. The latency of subcutaneous tumor formation is enhanced by mixing HMLER cells with Matrigel or early-passage human RMFs. (A) Comparison of the latency and rate of tumor formation of HEK cells ( ), BJ fibroblasts (ם), and HMECs (-) each expressing LT, hTERT, and H-rasV12. (B) The latency of tumor formation of HMLER cells $(\mathbf{O})$ was decreased by addition of Matrigel ( $\mathbf{0}$ ) or primary RMFs (RMF.1, $\bullet$ ). Results are expressed as the mean of six tumors +/- S.D. at the indicated time points after injection. 
vironment with Matrigel, a complex mixture of extracellular matrix proteins derived from the EnglebrethHolm-Swarm sarcoma (Kleinman et al. 1986), or stromal fibroblasts enhances the efficiency of tumor formation and decreases the tumor latency in other human breast cancer cell lines (Noel et al. 1993). To test whether modulation of the tumor microenvironment could affect the efficiency or latency of tumor formation of the HMLER cells, the three different populations of HMLER cells $\left(2 \times 10^{6}\right.$ cells $)$ expressing various levels of $\mathrm{H}$-ras V12 were mixed with equal volumes of PBS and Matrigel prior to subcutaneous injection. HMLER cells with highlevel H-rasV12 expression formed tumors in $100 \%$ of cases (12/12) and formed 13 days earlier on average than in the absence of admixed Matrigel (Fig. 6B). Tumor formation with a similarly short latency could also be observed with far fewer cells $\left(5 \times 10^{5}\right.$ cells, $6 / 6$ injections $)$. Tumors that formed with Matrigel were histologically similar to those that formed without Matrigel (data not shown). Tumors failed to form when $5 \times 10^{5}$ cells were injected in PBS alone (0/6 injections). Finally, addition of Matrigel to HMLER cells expressing low-level or intermediate-level H-rasV12 failed to elicit tumor formation (6 injections of each cell population) as observed as late as 12 weeks after injection.

We reasoned that we might create an even more physiologic microenvironment using stromal cells that are normally found within the human breast tissue and that the active stromal-epithelial interactions afforded by the presence of these cointroduced stromal cells would contribute positively to tumor formation of the HMLER cells. To test this notion, early-passage human mammary fibroblasts were isolated from reduction mammoplasty tissue and comingled with the HMLER cells in PBS prior to subcutaneous injection. For this experiment, we prepared two independent populations of reduction mammoplasty fibroblasts (RMFs) (termed RMF.1 and RMF.2) from two donors. We confirmed that these cells were fibroblasts by their lack of immunostaining with the AE1/AE3 broad-spectrum cytokeratin antibody and their positive staining for vimentin /data not shown). These two populations of early-passage fibroblasts were indistinguishable when their growth characteristics and their cytokeratin and vimentin staining were compared.

Each of these RMF preparations was mixed as a singlecell suspension with the three different populations of HMLER cells expressing various levels of H-rasV12 at a ratio of $1: 1\left(1 \times 10^{6}\right.$ cells of each type) prior to being injected subcutaneously in nude mice. Mixing of RMFs with HMLER cells expressing high-level H-rasV12 enhanced the efficiency of tumor formation (6/6) compared with the 14/27 efficiency observed when $2 \times 10^{6}$ HMLER cells were injected alone. In addition, the latency of tumor formation was dramatically decreased following admixture of RMFs. The mixture of HMLER cells with RMFs resulted in palpable tumor formation at an average of 20 days as compared with HMLER cells alone (52 days) or HMLER cells mixed with Matrigel prior to injection (39 days) (Fig. 6B). The RMF.1 and RMF.2 fibroblast populations behaved indistinguishably in these tumorigenicity assays and, as anticipated, failed to form tumors when injected alone (data not shown).

Mixing of RMFs with HMLER cells containing lowlevel or intermediate-level H-rasV12 failed to produce tumors (0/6 injections with each HMLER population). Furthermore, comingling of HMLER cells expressing low or intermediate-level H-rasV12 with both RMFs and Matrigel failed to induce tumor formation $10 / 3$ injections with each HMLER population). Thus, the more hospitable tumor microenvironment provided by cointroduced mammary fibroblasts and Matrigel could not substitute for high level expression of H-rasV12.

The tumors derived from these mixed populations of fibroblasts and HMLER cells expressing high-level H-rasV12 were histologically similar to those tumors that arose when the HMLER cells were injected alone. The tumors were comprised predominantly of undifferentiated epithelial tumor cells $(\sim 80 \%-90 \%$ of the tumor mass) whether they were derived from injections of HMLER cells alone or mixed populations of HMLER cells and mammary fibroblasts.

\section{Growth properties of HMLER cells in comparison with the explanted tumor cells}

These observations suggested that the three introduced genes were sufficient for tumorigenic conversion of primary HMECs; however, the possibility remained that additional genetic changes occurred in vivo during tumor formation. If this had occurred, cells explanted from the initially formed tumors would be expected to have acquired growth or tumorigenic properties distinct from those associated with the parental cells that had never been injected into host mice. To test this possibility, we isolated two populations of explanted tumor cells from HMLER tumors that had formed in the presence of Matrigel (HMLER.NT1 and HMLER.NT2). These two explanted populations of cells had growth rates in vitro virtually identical to those of the parental population (Fig. 7A) and formed a similar number of colonies when grown in soft agar (Fig. 7B). Furthermore, when these cells were reinjected subcutaneously into nude mice in the presence of Matrigel, tumors formed with a latency similar to that associated with cells that had never been passaged as tumor cells through mice (Fig. 7C). These observations made it unlikely that these tumor cells, following their initial injection into host mice, had sustained one or more additional changes that were necessary and rate limiting for their tumorigenic ability.

\section{Karyotype analysis of transformed HMECs}

Whereas the above experiments lessened the likelihood that the tumor cells had sustained additional genetic changes following the introduction of the LT, hTERT, and ras genes, it remained possible that other requisite genetic changes had occurred in these cells prior to their manipulation by us or during their in vitro passaging 

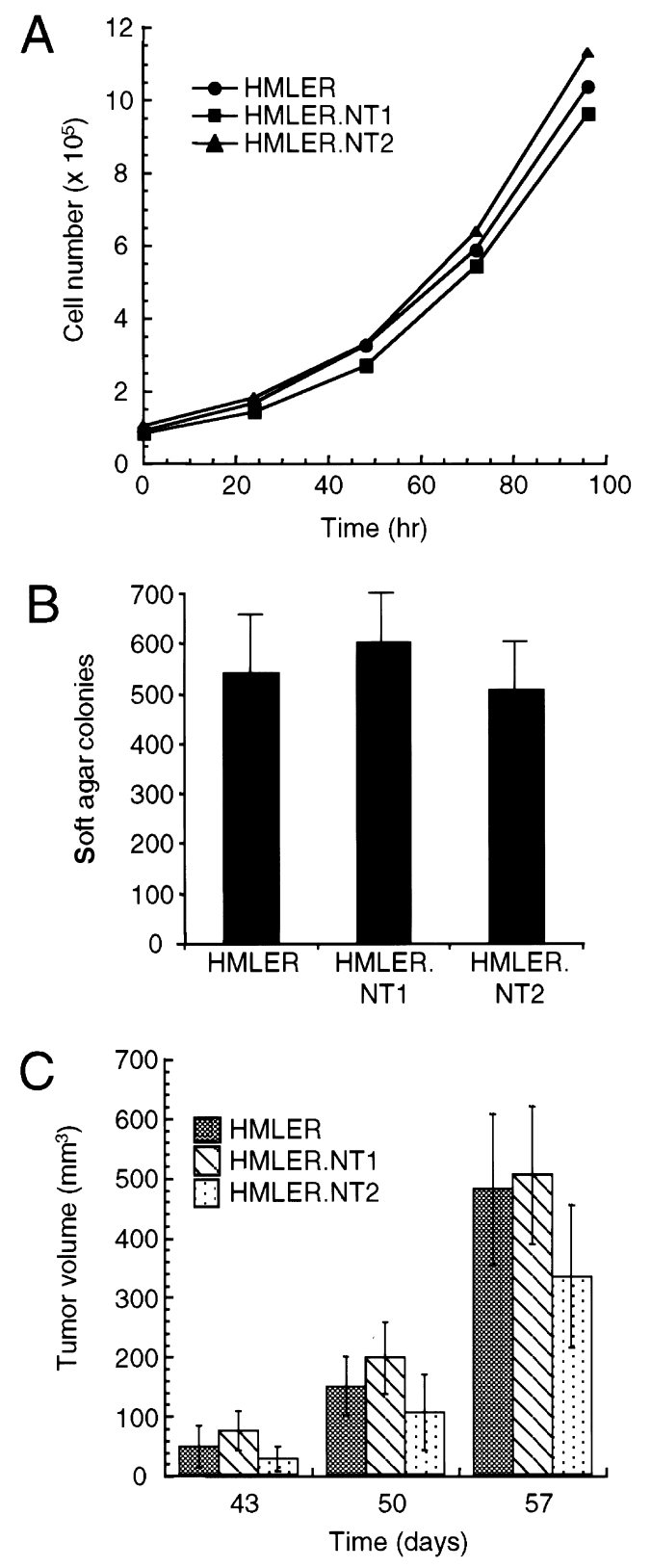

Figure 7. Growth properties of two explanted tumor cell populations in comparison to the parental HMLER cells. $(A)$ The in vitro growth rate of two populations of HMLER cells explanted from independent tumors (HMLER.NT1 and HMLER.NT2) was compared with that of the parental HMLER cells. The growth rate of HMLER cells is indicated by $\bullet$, HMLER.NT1 by $\boldsymbol{m}$, and HMLER.NT2 by $\boldsymbol{\Delta}$. (B) Anchorage-independent growth of the same three populations of cells. Results are expressed as the mean of three experiments +/- S.D. for $5 \times 10^{4}$ cells. (C) Subcutaneous tumor formation of the three populations of cells with Matrigel addition. Results are expressed as the mean of 6 tumors +/- S.D. at the indicated time points after injection. $(D)$ Immunoblot analysis of c-Myc protein in the indicated populations of HMECs and in the HMLER.NT1 and HMLER.NT2 cells.

prior to injection into mice. Such changes, to the extent that they had occurred, might well be required together with these introduced genes to achieve the observed tumorigenicity.

We considered it likely that such additional changes might well be apparent at the karyotypic level. Accordingly, we performed spectral karyotype analysis (SKY) and fluorescence in situ hybridization (FISH) on the HMECs expressing LT, hTERT, and either low or highlevels of H-ras V12 prior to their injection into mice. SKY analysis revealed that both populations contained mixtures of near-diploid and near-tetraploid cells and that all cells in these populations showed an abnormal karyotype regardless of ploidy (Table 2). Of note, both of these cell populations contained cells showing a variety of additional, idiosyncratic karyotypic changes, indicating that these populations were polyclonal. This provided further evidence against the notion that the observed tumorigenicity of the high Ras-expressing HMLER cells derived from some type of additional rare genetic alteration followed by the outgrowth of the resulting variant subpopulation.

Interestingly, the low and high Ras-expressing populations each carried distinct types of chromosome 8 alterations that caused an increase in the copy number of the c-myc gene. In the nontumorigenic HMECs expressing low-level H-rasV12, 50\% of the cells had trisomy 8 (Fig. $8 \mathrm{~A})$, and $6 \%$ of the cells contained a rearranged chromosome $\mathrm{t}(3 ; 8 ; \mathrm{X})$. Both changes resulted in additional copies of c-myc (three or six copies of c-myc in diploid and tetraploid cells, respectively) as observed by c-myc FISH analysis (Fig. 8B). Other structural changes included a $t(7 ; 9)$ in $50 \%$ of the cells that was always accompanied by loss of one $9 \mathrm{p}$ and trisomy 8 , and a deletion of $12 \mathrm{p}$ in $22 \%$ of the cells.

The tumorigenic HMECs expressing high-level H-rasV12 contained a different chromosome 8 alteration, resulting in an additional copy of c-myc. These cells had an unbalanced translocation $\mathrm{t}(3 ; 8)$, in which a small distal segment of chromosome 8 was translocated to the distal part of the long arm of chromosome 3 (Fig. $8 \mathrm{C})$. This translocation is similar, but not identical, to the portion of the derivative chromosome $\mathrm{t}(3 ; 8 ; \mathrm{X})$ observed in $6 \%$ of the HMECs expressing low levels of Ras. FISH analysis for c-myc showed that chromosomes bearing the $\mathrm{t}(3 ; 8)$ translocation contained three or six copies of c-myc in diploid and tetraploid cells, respectively (Fig. $8 \mathrm{D})$. On the basis of the combination of SKY, DAPI-generated $\mathrm{G}$ banding, and FISH, we define the translocation as $\mathrm{t}(3 ; 8)(\mathrm{q} 29 ; \mathrm{q} 23-24.3)$. Although this translocation involves the portion of chromosome 8 in which c-myc resides, we did not detect evidence of a translocation breakpoint contained within the 12.5-kb c-myc locus by Southern blot analysis (Fig. 8H).

Next, we sought to determine whether the selection for c-myc amplification was specific to these particular HMECs (Clonetics) or alternatively whether this and similarly acting karyotypic alterations represented a more general trait of HMEC populations grown in vitro. To test this hypothesis, we performed SKY and FISH analyses on the population of transformed PHMECs, which we had prepared directly from a reduction mam- 
Table 2. Karyotype and c-myc amplifications in transformed HMECs

\begin{tabular}{|c|c|c|}
\hline Cells & Genotype & Karyotype and c-myc copy number \\
\hline \multirow[t]{4}{*}{ HMEC } & LT, hTERT, Ras-hygro & $\begin{array}{l}90 \% \text { were near-diploid; } 10 \% \text { were near-tetraploid. } 50 \% \text { had trisomy } 8 \text { resulting } 3 \text { to } 6 \\
\text { copies of c-myc in diploid and tetraploid cells, respectively. These cells also contained } \\
t(7 ; 9) \text { and loss of one } 9 \mathrm{p} \text {. } \\
22 \% \text { contained a deletion of } 12 \mathrm{p} \text {. } \\
6 \% \text { had } \mathrm{t}(3 ; 8 ; \mathrm{X}) \text {. }\end{array}$ \\
\hline & LT, hTERT, Ras-puro & $62 \%$ were near-diploid; $38 \%$ were near-tetraploid. \\
\hline & & $\begin{array}{l}100 \% \text { had } \mathrm{t}(3 ; 8)(\mathrm{q} 29 ; \mathrm{q} 23-24.3) \text { resulting in } 3 \text { or } 6 \text { copies of } \mathrm{c}-\mathrm{myc} \text { in diploid and tetraploid } \\
\text { cells, respectively. }\end{array}$ \\
\hline & & Cells contained other sporadic changes. \\
\hline \multirow[t]{3}{*}{ PHMEC } & LT, hTERT, Ras-puro & $100 \%$ were near-tetraploid. \\
\hline & & $75 \%$ had iso(8q) with $5-10$ copies of $c-m y c$ and had $t(1 ; 7)$ and $t(6 ; 10)$. \\
\hline & & Cells without iso(8q) gained extra copies of 5 and 9 . \\
\hline
\end{tabular}

moplasty, following introduction of the three genes. Surprisingly, these cells also contained a structural change in chromosome 8 resulting in $\mathrm{c}-m y c$ amplification through another, quite distinct mechanism. PHMECs expressing LT, hTERT, and Ras contained a mixture of hypo- and hyper-tetraploid cells with chromosome numbers ranging from 81 to 111 . Although many random translocations were observed, we detected the presence of an isochromosome 8 [iso( $8 \mathrm{q})]$ in $75 \%$ of the cells (Fig. $8 \mathrm{E})$. This distinctive abnormality resulted in loss of the short arm of chromosome 8 and duplication of its entire long arm, including the c-myc locus. Some of the cells contained two copies of this derivative chromosome. Thus, the c-myc gene copy number in cells containing the iso(8q) ranged from five (Fig. 8F) to ten (Fig. 8G). Cells bearing iso $(8 \mathrm{q})$ also contained two recurrent translocations, $\mathrm{t}(1 ; 7)$ and $\mathrm{t}(6 ; 10)$, whereas the $25 \%$ of cells lacking this iso(8q) gained extra copies of chromosomes 5 and 9.

Taken together, we conclude that all of the transformed HMEC described here, which were derived originally from two independent reduction mammoplasty samples, contained a moderate level of c-myc gene amplification, albeit achieved by three distinct chromosomal alterations, trisomy 8 , a nonrandom translocation $\mathrm{t}(3 ; 8)$, and formation of isochromosome $8(\mathrm{q})$. Although amplification of c-myc is the most likely candidate gene that was selected for in these cells, we cannot exclude the possibility that other genes residing on the long arm of chromosome 8 provide a growth advantage to the HMECs in culture. Significantly, we did not observe similar structural and numerical alterations in the $8 \mathrm{q} 24$ region in either the kidney epithelial or fibroblast lines transformed with LT, hTERT, and Ras (data not shown). Thus, this selection, presumably for increased c-myc copy number, is specific to HMECs and occurred during the in vitro growth of these transformed HMECs.

We next sought to determine the effects, if any, of this c-myc gene amplification on the steady state level of $\mathrm{c}-m y c$ protein in proliferating cultures. Immunoblot analysis showed a modest increase in the level of c-Myc protein (1.5-2.5 fold) in the transformed HMEC in comparison to primary HMEC cultures (Fig. 8I). This observed increase in c-Myc protein level is similar to that recently reported in HMECs immortalized by hTERT alone (Wang et al. 2000).

\section{Discussion}

These experiments establish a new experimental system for understanding the cell-autonomous and non-cell-autonomous etiology of breast cancer. Starting with primary HMECs isolated from reduction mammoplasty tissue, we have succeeded in transforming such cells to tumorigenicity through the introduction of a limited set of oncogenes. Significantly, the biological behavior of such transformed cells depended on specific genetic alterations as well as stromal-epithelial interactions.

Although the genetic elements used in these experiments do not correspond directly to those mutated in human breast cancers, we believe that the regulatory pathways disrupted by these three genes are commonly and perhaps invariably altered in such naturally arising tumors. Thus, we suspect that inactivation of the p53 and $\mathrm{pRB}$ proteins by LT mimics the functional inactivation of the p53 and pRB regulatory pathways that occurs in breast cancers (Varley et al. 1989; Ozbun and Butel 1995; Brenner et al. 1996). However, we cannot exclude the possibility that LT has additional activities that contribute to its ability to cooperate in tumorigenesis. In addition, we note that the LT retrovirus vector used in these studies encodes both the large $\mathrm{T}$ and small $\mathrm{t}$ antigens, both of which may play a role in the observed cell transformation (W.C. Hahn, J.A. DeCapri, and R.A. Weinberg, in prep.). Because most breast cancers maintain their telomeres by the activation of telomerase activity (Shpitz et al. 1999), the ectopic expression of hTERT described here closely mimics a change that occurs during the progression of spontaneously arising breast cancers. Lastly, although the ras gene is rarely mutated in breast cancers $(-5 \%$ of cases), evidence suggests that most breast cancers have alterations in the Ras-signaling pathway (Clark and Der 1995), one common mechanism being overexpression of HER-2/neu, a known upstream activator of Ras signaling.

Unexpectedly, we found that the transformed HMECs that emerged following introduction of LT, hTERT and 

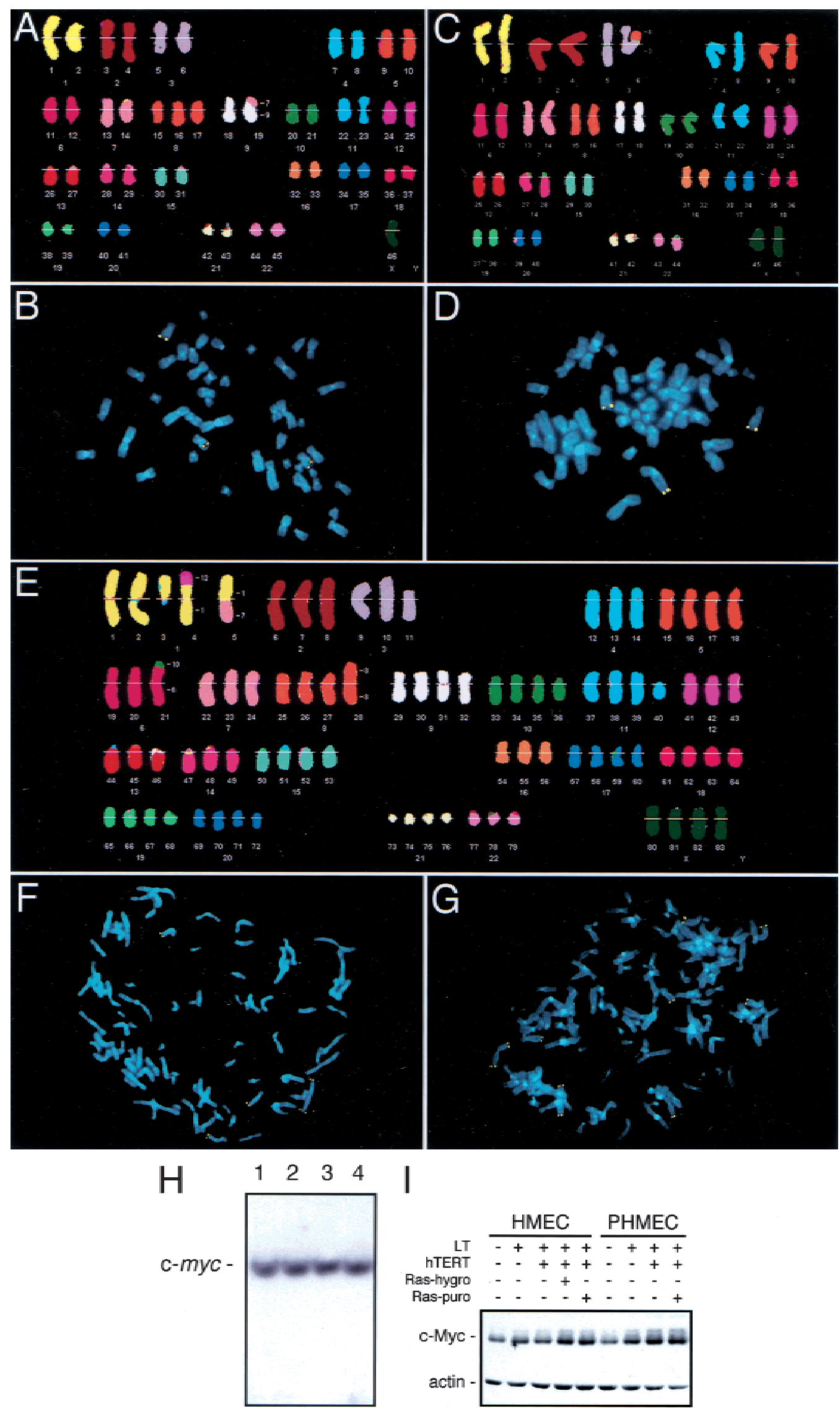

Figure 8. (See facing page for legend.) 
H-rasV12 carried c-myc amplifications. The origins of these amplifications are unclear as they may have arisen due to the physiologic pressures of in vitro passaging or pressures exerted by the introduced genes. This finding is remarkable in several respects. First, three distinct types of chromosomal alterations involving duplication of $8 \mathrm{q} 24$ were found in the HMECs, trisomy 8 , an unbalanced translocation $\mathrm{t}(3 ; 8)$, and isochromosome $8(\mathrm{q})$. Furthermore, these changes occurred in HMECs derived from two independent reduction mammoplasty tissue samples. Lastly, we have not observed these specific chromosomal alterations in two extensively characterized cell types (BJ fibroblasts and HEK cells) transformed by LT, hTERT, and H-rasV12, suggesting that this change is specific to the HMECs.

The portion of chromosome 8 amplified by these changes includes the c-myc locus. We observed modest amplification of c-myc copy number and concomitant increases in c-Myc protein. Although we cannot eliminate the possibility that this increase in c-myc expression is required for both the growth of such cells in vitro and during tumor formation, we found that c-myc expression is elevated in HMECs prior to their injection into mice. It is possible that these alterations affecting c-myc gene copy number occur spontaneously in HMECs passaged in vitro, without any of the manipulations described herein. Wang et al. (2000) have reported recently that HMECs immortalized by hTERT, when grown extensively in vitro, also show increases in c-Myc expression, compatible with the possibility that hTERT expression may favor the in vitro proliferation of cells expressing increased levels of c-Myc. At present, we cannot distinguish among these possibilities; however, it is interesting to note that expression of $\mathrm{c}-m y c$ has been shown to block differentiation in several in vitro cell culture models (Facchini and Penn 1998) and may partially explain the poorly differentiated phenotype of the carcinomas formed by transformation of HMECs.

The c-myc amplifications described here mimic those that occur in naturally arising human breast tumors. In fact, recent comparative genomic hybridization (CGH) and SKY studies of primary breast cancers and cell lines have shown recurrent gain of 8q (Tirkkonen et al. 1988; Kyotola et al. 2000; Zimonjic et al. 2000). Overall, a gain of $8 \mathrm{q}$ was found in $49 \%$ of breast cancers (Tirkkonen et al. 1988). The observation that the in vitro transformation of HMECs described here is associated with amplifications of c-myc similar to that observed in some breast cancers incorporates an important feature of breast carcinogenesis in this model.

Transformation of human cells with the combination of LT, hTERT, and H-rasV12 requires high-level expression of H-ras V12. We suspect that this high-level expression of mutant ras does not closely approximate the situation observed in human tumors that contain a mutated ras gene. There is little evidence in human tumors that ras alleles containing point mutations become highly overexpressed (more than fivefold) due to gene amplification or overexpression (Bos 1988). We speculate that the replacement of $\mathrm{LT}$ and hTERT with other genes known to be involved in naturally arising breast cancers may enable HMECs to be transformed with lower levels of oncogenic ras that more closely approximate those observed in human tumors.

Whereas mutant ras alleles have not been found to be strongly overexpressed in human breast tumors, it is clear that the level of ras expression is a critical determinant of tumorigenicity in two well-studied rodent tumor models. In a mouse skin carcinogenesis model, carcinogen treatment initiates benign papilloma formation through mutation of H-ras (Balmain et al. 1988). The subsequent progression of papillomas to carcinomas is associated with an increased expression of the mutant ras allele achieved either by gene amplification or mRNA overexpression (Harper et al. 1986; RodriguezPuebla et al. 1999). In addition, transformation of Rat1 fibroblasts by a mutant H-ras 1 allele is achieved only by high-level expression of the mutant allele (Finney and Bishop 1993).

The biochemical explanation for the requirement for high-level expression of H-rasV12 in the transformation of cells expressing LT and hTERT remains elusive. One possibility is that the intense Ras-mediated signaling associated with high-level expression activates one or more of the downstream signaling pathways controlled by Ras such as the MAP kinase and PI3 kinase pathways to a level that is essential for tumorigenesis by the transformed cells. Alternatively, high-level H-rasV12 may activate other downstream signaling pathways that are not normally perturbed by lower levels of H-rasV12. Distin-

Figure 8. Spectral karyotype (SKY) and FISH analysis of transformed HMEC and PHMEC cells. (A) Spectral classified karyotype of a near-diploid nontumorigenic HMEC cell (LT, hTERT, and low-level H-rasV12) showing trisomy of chromosome 8 and the translocation $\mathrm{t}(7 ; 9)$. (B) Metaphase from $A$ exhibiting three copies of c-myc gene. $(C)$ Spectral classified karyotype of a near-diploid tumorigenic HMEC cell (LT, hTERT, and high-level H-rasV12) showing translocation $\mathrm{t}(3 ; 8)$ as the only genomic rearrangement. $(D)$ Metaphase from $C$ with three copies of $\mathrm{c}-\mathrm{myc}$ gene. One copy of c-myc is located on derivative chromosome 3 featuring translocation $\mathrm{t}(3 ; 8)(\mathrm{q} 29 ; \mathrm{q} 23-$ 24.3). (E) Spectral classified karyotype of a near-tetraploid tumorigenic PHMEC cell (LT, hTERT, and high-level H-rasV12) revealing the presence of one isochromosome $8(\mathrm{q})$, recurrent translocations $\mathrm{t}(1 ; 7)$ and $\mathrm{t}(6 ; 10)$, and additional random changes $\mathrm{t}(1 ; 12)$, del $(1 \mathrm{q})$, $\operatorname{del}(3 \mathrm{p})$, and del(11p). (F) Metaphase from a hypo-tetraploid tumorigenic PHMEC cell (LT, hTERT, and H-rasV12) after FISH with genomic c-myc probe, showing five copies of c-myc gene. (G) Metaphase from a hyper-tetraploid tumorigenic PHMEC cell (LT, hTERT, and $\mathrm{H}$-ras V12) showing six copies of c-myc on six normal chromosomes 8 and additional four copies of c-myc gene located on two isochromosomes 8(q). (H) Southern blot analysis for c-myc of HMECs expressing LT (lane 1) or the combination of LT, hTERT, and high-level H-rasV12 (lane 2), PHMECs expressing LT (lane 3), or the combination of LT, hTERT, and high-level H-rasV12 (lane 4). (I) Immunoblot analysis of c-Myc and actin from the indicated cells. The normalized levels of c-Myc in the indicated cells as compared with the primary HMEC or PHMEC (first lane of each group) were HMECs expressing LT, hTERT, and Ras-hygro (1.5), HMECs expressing LT, hTERT, and Ras-puro (1.4), and PHMECs expressing LT, hTERT, and Ras-puro (2.5). 
guishing between these alternatives is complicated by the numerous downstream-signaling pathways that are influenced by Ras (Campbell et al. 1998).

Histological analysis of these tumors revealed that they were poorly differentiated carcinomas that were invasive, as characterized by infiltration into several types of neighboring tissue. However, an unambiguous designation of these tumors as being invasive is complicated by the manner in which the tumors formed. These tumors arose following injection into tissue and were therefore introduced into microenvironments very different from those experienced by tumor cells arising autochthonously. The frequently used definition of invasiveness, involving spreading through adjacent basement membranes, could not be invoked here, as the engrafted cells did not reside initially in close juxtaposition with pre-existing basement membranes. In addition, we did not observe metastatic lesions in mice harboring tumorigenic HMLER cells, suggesting that additional genetic or epigenetic changes may be necessary to acquire a fully malignant phenotype.

Tumor formation by the HMLER cells at subcutaneous sites was inefficient, occurring in only half of the injections, and the tumors developed with a long latency. Suspecting that the stromal microenvironment of the subcutaneous site may be inadequate for tumor formation by the transformed HMECs, we also examined their tumorigenicity in the orthotopic site. Surprisingly, the subcutaneous site provided a more favorable environment for the growth of the HMLER cells than did the mammary gland. This observation may be explained by the fact that the stroma of the human and mouse mammary glands are quite different. The majority of the mouse gland is composed of adipocytes with the fibroblasts prominent only in narrow sheaths around the ducts. In the human gland, the ducts are embedded in large tracts of connective tissue (composed predominantly of fibroblasts) that is adjacent to deeper layers of adipose tissue (Hovey et al. 1999). Human mammary epithelial tumor cells may therefore require and thrive in the specialized stromal microenvironment of the human gland rather than the largely adipose tissue microenvironment of the mouse mammary gland.

The addition of Matrigel basement membrane matrix or primary mammary fibroblasts to the HMLER epithelial tumor cells dramatically enhanced the efficiency of tumor formation and decreased the latency of tumor formation. Matrigel and fibroblasts may enhance tumorigenicity by similar mechanisms, as Matrigel is derived from a sarcoma and may contain extracellular matrix factors similar to those that are deposited by the primary fibroblasts. However, the latency of tumor formation by the transformed HMECs was markedly shorter with admixed stromal fibroblasts than with admixed Matrigel. This suggests that the continued growth of the fibroblasts and their secretion of extracellular matrix and growth factors promote tumor growth more efficiently than Matrigel, whose role may be limited to enhancing the initial establishment of implanted tumor cells in the host tissue.
Cunha and colleagues have investigated previously the tumor-promoting effect of fibroblasts on carcinoma formation in a prostate carcinoma model system /Olumi et al. 1999). They showed that human carcinoma-associated fibroblasts, but not normal fibroblasts, stimulated the tumorigenicity of an initiated prostate epithelial cell line. This finding suggests that fibroblasts within carcinomas have undergone functional changes during tumorigenesis, resulting in their enhanced ability to promote tumor formation. Here, we have shown that normal, early-passage mammary fibroblasts also dramatically stimulate tumor formation. Comparison of the tumor-promoting activities of various fibroblast populations, including tumor-associated breast fibroblasts, with these normal fibroblasts will define the phenotypic characteristics and biochemical activities of fibroblasts that determine their effectiveness at promoting carcinoma formation.

Using this experimental approach of genetically transforming HMECs, we can now further refine this experimental model to more accurately mimic the genetic changes that occur in spontaneously arising human breast cancers. Thus, the LT, hTERT, and H-rasV12 genes can be replaced with other genes known to be involved in human breast cancers such as cyclin D1, HER2/neu and ER. This will enable us to test, for example, whether overexpression of cyclin D1 mimics the inactivation of $\mathrm{pRB}$ achieved by LT or whether overexpression of HER-2/neu can substitute for H-rasV12. Furthermore, incorporation of ER into this system may enable us to create new estrogen-dependent models of breast cancer.

The creation of new populations of breast cancer cells with genes found mutated in naturally arising breast cancers will be useful in several respects. First, this will lead to a clearer understanding of the contributions of different genes to the transformation process and provide new populations of breast tumor cells that can be used to test novel molecule-based therapies. Second, genes suspected to play roles in promoting later stages of tumorigenesis including metastasis can be introduced into these cells and their effects analyzed. Lastly, one can determine whether a particular gene creates a tumor phenotype that differs from that observed with HMECs expressing LT, hTERT, and H-rasV12. It is now possible to test whether other genes known to be involved in breast cancer will yield more differentiated malignancies that more closely resemble either ductal carcinoma in situ or lobular carcinoma. In this way, it may be possible to link the genotypes of cancer cells with specific clinical and histopathological features of the tumors.

\section{Materials and methods}

Culture of HMECs and mammary fibroblasts

HMECs (Clonetics) were cultured in MEGM at $37^{\circ} \mathrm{C}$ with $5 \%$ $\mathrm{CO}_{2}$ as described (Stampfer 1985). MEGM is a serum-free medium composed of modified MCDB 170 basal medium with supplements. We isolated a second population of HMECs (PHMECs) from reduction mammoplasty tissue as described (Stampfer 1985). Human RMFs were isolated from reduction 
mammoplasty tissue by similar methods except that the tissue was incubated overnight with both collagenase (Sigma 225 units $/ \mathrm{ml}$ ) and hyaluronidase (Sigma 125 units/ml). The cells and organoids were then washed and plated in Dulbecco's Modified Eagle's Medium (DMEM) with 10\% FBS. On reaching confluence, the fibroblasts were separated from the epithelial cells by differential trypsinization as described (Olumi et al. 1999). The predominance of fibroblasts and the absence of epithelial cells in the second passage of primary cells was confirmed by immunofluorescence staining for vimentin and the lack of staining with the broad spectrum, cytokeratin antibody AE1/AE3. Both the primary epithelial cells and fibroblasts were subcultured $1: 4$ on reaching confluence; each passage was considered two PD.

\section{Immunofluorescence and histology}

HMECs and fibroblasts were grown on glass cover slips preincubated in a 1:1 mixture of calf serum and PBS. Cells were fixed with $2 \%$ paraformaldehyde, $0.1 \%$ Triton X-100. Cells were incubated with the following antibodies: cytokeratin 14 (CKB1, Sigma), cytokeratin 18 (cy-90, Sigma), cytokeratin 19 (A53-B/ A2, Sigma), cytokeratin AE1/AE3 (Chemicon), $\alpha$-smooth muscle actin (1A4, Dako), vimentin (vim 13.2, Sigma), E-cadherin (clone 36, Transduction Laboratories), and ER- $\alpha$ (HC-20, Santa Cruz).

Tumors were fixed in $10 \%$ formalin, embedded in paraffin, and sections stained with hematoxylin and eosin according to standard procedures. Immunohistochemical staining was carried out by use of the conventional $\mathrm{ABC}$ technique and heatinduced epitope retrieval. The primary antibodies used were as follows: the cytokeratin antibody AE1/AE3, ER (ID5, Dako) and $\alpha$-smooth muscle actin IA4.

\section{Retroviral infections}

Retroviral infections were performed serially with drug selection used to purify polyclonal-infected populations after each infection. To create amphotropic retroviruses, $10-\mathrm{cm}$ dishes of $293 \mathrm{~T}$ cells were cotransfected with $8 \mu \mathrm{g}$ each of the amphotropic packaging plasmid pCL-10A1 (Imgenex) and the specified pBabe retroviral expression construct (Morgenstern and Land 1990) by calcium phosphate precipitation. Viral supernatants were harvested at $28 \mathrm{hr}$ and used to infect HMECs with $8 \mu \mathrm{g} / \mathrm{ml}$ polybrene. Typically, $20 \%-40 \%$ infection of the HMECs was achieved by use of this protocol as measured by parallel infections with a GFP-expressing retrovirus. pBabe-zeo was created by replacement of the puromycin resistance gene in pBabe-puro with zeocin from $\mathrm{pVgRXR}$ (Invitrogen). Infections with LT were performed with the ecotropic LT producer cell line $\psi_{2}$, simian virus 40 (Jat et al. 1986) that expresses LT from a genomic portion of the SV40 early region. Amphotropic LT retrovirus was generated by transient infection of the PT67 producer cell line (Clontech). Drug selection of infected HMECs was performed with $200 \mu \mathrm{g} / \mathrm{ml}$ G418 for neomycin (neo), $50 \mu \mathrm{g} / \mathrm{ml}$ hygromycin (hygro), $0.5 \mu \mathrm{g} / \mathrm{ml}$ puromycin (puro), or $500 \mu \mathrm{g} / \mathrm{ml}$ zeocin (zeo).

\section{Immunoblotting, RT-PCR analysis, and telomerase assays}

Expression of the SV40 LT, H-Ras, p16 ${ }^{\mathrm{INK} 4 \mathrm{a}}$, and c-Myc proteins was measured by immunoblotting of $75-\mu \mathrm{g}$ total cellular proteins with the LT antibody PAb 101 (Santa Cruz), the H-Ras C-20 antibody (Santa Cruz), the p16 $6^{\text {INK4a }}$ antibody G175-405 (Pharmingen), the c-Myc 9E10 antibody (Santa Cruz), and the actin antibody AC-40 (Sigma-Aldrich Chemical Co). Blots were developed by ECL chemiluminescent detection (Amersham). RT-PCR for $h T E R T$ was performed by preparation of total RNA with RNA Stat-60 (Tel-Test) followed by the single-step RTPCR analysis (Life Technologies). In each reaction, $100 \mathrm{ng}$ of total RNA was amplified using primers for the retroviral encoded hTERT and the endogenous GAPDH (Hahn et al. 1999). Telomerase activity was measured by the PCR-based telomeric repeat amplification protocol (TRAP) assay.

\section{Soft agar assays}

For HMEC soft agar assays, a bottom layer of $0.6 \%$ agar noble in DMEM without serum was first placed onto $6-\mathrm{cm}$ dishes. HMECs were seeded in $0.3 \%$ top agar containing MEGM. Fresh top agar was added after $1.5 \mathrm{wk}$, and colonies were counted after 3 wk. HEK cells were grown under similar conditions except that the cells were grown in DMEM with 10\% FBS.

\section{Subcutaneous tumorigenicity assays}

Six- to eight-week-old immunocompromised athymic nude mice (Balb/c-ByJ-Hfh $11^{\text {nu }}$, Jackson Laboratory) were $\gamma$-irradiated with $400 \mathrm{rad} 4 \mathrm{hr}$ prior to injection. Irradiation with this dose may suppress natural killer cell activity (Feuer et al. 1995) and/ or may create a more permissive environment for the growth of tumor cells (Barcellos-Hoff and Ravani 2000). Cells $\left(2 \times 10^{6}\right)$ were resuspended in $200 \mu \mathrm{l}$ of PBS and injected with a 25 -gauge needle into anaesthetized mice. For Matrigel (Becton Dickinson) injections, cells were resuspended in $100 \mu \mathrm{l}$ of PBS and 100 $\mu \mathrm{l}$ of Matrigel. Tumor size was measured every 3-4 days. The time of initial tumor formation was defined as the time when the tumor had reached a diameter of $3 \mathrm{~mm}$. Mice were sacrificed when the tumors grew to $1 \mathrm{~cm}$ in diameter or after $12 \mathrm{wk}$ of monitoring. Tumor volume was calculated with the formula $4 / 3 \pi r^{3}$. Tumors were fixed in $10 \%$ formalin for histological examination or the tumor cells were reisolated for subsequent analysis. Tumor cells were reisolated by mincing the tumor, incubation in collagenase for $4 \mathrm{hr}$, washing the cells in PBS, and replating the cells in MEGM.

\section{Orthotopic tumorigenicity assays}

Six-week-old immunocompromised $R A G 1^{-/-}$mice (Mombaerts et al. 1992) were $\gamma$ irradiated with $400 \mathrm{rad} 4 \mathrm{hr}$ prior to surgery. Mice were anesthetized with avertin intraperitoneal and the inguinal mammary glands exposed for injection. Cells $\left(2 \times 10^{6}\right)$ were resuspended in $25 \mu \mathrm{l}$ of PBS and injected with a Hamilton syringe and a 25-gauge needle. The incision was closed with surgical staples. Mice were sacrificed and the mammary glands excised for histological analysis after 10 wk or earlier when tumors were visible.

\section{Karyotype analysis}

Chromosomes were prepared by use of an improved procedure for chromosome preparation from solid tumors (Zimonjic and Popescu 1994) and kept at room temperature for 5-6 days prior to hybridization for SKY analysis. SKY analysis was performed as originally described (Schrock et al. 1996). The chromosome probe cocktail was labeled by Spectrum Orange, Texas Red, CY5, Spectrum Green, and Cy5. 5, denatured, and hybridized on denatured target slides. Visualization for biotin- and digoxigenin-labeled DNAs of the probe cocktail was carried out with avidin-Cy5 (Amersham) and antidigoxigenin-Cy5.5 (Sigma) antibodies. An interferogram for each metaphase was generated using a SD200 Spectracube (Applied Spectral Imaging) mounted on a Zeiss Axioscope II fluorescent microscope equipped with a custom-made optical filter (Chroma Technology). Spectral in- 
formation, upon recovery by Fourier transformation, was used to produce a multicolor digital image with red, green, and blue colors assigned to certain ranges of recorded spectrum. Further analysis and classification were performed in SKY View 1.5 karyotyping software (Applied Spectral Imaging) using a Windows NT Workstation.

Biotin- and digoxigenin-labeled painting probes for short and long arms of chromosomes 3 and 8 (AL Technologies), and a genomic c-myc probe (Ventana Medical Systems) were used for FISH. Detection of the hybridization signal, digital image acquisition, and analysis were carried out as described previously (Zimonjic et al 1995). For each line, SKY results are based on 15-20 spectral and inverted DAPI-banded karyotypes and FISH data on 50 randomly examined spreads. Southern blot analysis of c-myc was performed on EcoRI-digested genomic DNAs using a $1.5-\mathrm{kb}$ SacI-BgIII fragment encompassing exon 2 of c-myc as a probe.

\section{Acknowledgments}

We thank the members of the Weinberg laboratory for helpful discussions, M. Planas-Silva for expert advice on the propagation of primary HMECs from reduction mammoplasty tissue samples, and C. Griffin for excellent technical assistance. This work was supported in part by grants from the National Cancer Institute (5 P01 CA80111-02) and the G. Harold and Leila Y. Mathers Charitable Foundation. B.E. was supported by an American Cancer Society postdoctoral fellowship and W.C.H. was supported by a Howard Hughes Medical Institute postdoctoral fellowship and a Doris Duke Charitable Foundation Clinical Scientist Award. L.S. is a special fellow of the Leukemia and Lymphoma Society. R.A.W. is an American Cancer Society Research Professor and a Daniel K. Ludwig Cancer Research Professor.

The publication costs of this article were defrayed in part by payment of page charges. This article must therefore be hereby marked "advertisement" in accordance with 18 USC section 1734 solely to indicate this fact.

\section{References}

Balmain, A., Brown, K., Akhurst, R.J., and Fee, F.M. 1988. Molecular analysis of chemical carcinogenesis in the skin. Br. J. Cancer Suppl. 9: 72-75.

Band, V., De Caprio, J.A., Delmolino, L., Kulesa, V., and Sager, R. 1991. Loss of p53 protein in human papillomavirus type 16 E6-immortalized human mammary epithelial cells. J. Virol. 65: 6671-6676.

Barcellos-Hoff, M.H. and Ravani, S.A. 2000. Irradiated mammary gland stroma promotes the expression of tumorigenic potential by unirradiated epithelial cells. Cancer Res. 60: $1254-1260$.

Bartek, J., Durban, E.M., Hallowes, R.C., and Taylor-Papadimitriou, J. 1985. A subclass of luminal epithelial cells in the human mammary gland, defined by antibodies to cytokeratins. J. Cell Sci. 75: 17-33.

Bos, J.L. 1988. The ras gene family and human carcinogenesis. Mutat. Res. 195: 255-271.

Brenner, A.J., Paladugu, A., Wang, H., Olopade, O.I., Dreyling, M.H., and Aldaz, C.M. 1996. Preferential loss of expression of p16(INK4a) rather than p19(ARF) in breast cancer. Clin. Cancer Res. 2: 1993-1998.

Campbell, S.L., Khosravi-Far, R., Rossman, K.L., Clark, G.J., and Der, C.J. 1998. Increasing complexity of Ras signaling. On- cogene 17: 1395-1413.

Clark, G.J. and Der, C.J. 1995. Aberrant function of the Ras signal transduction pathway in human breast cancer. Breast Cancer Res. Treat. 35: 133-144.

Escot, C., Theillet, C., Lidereau, R., Spyratos, F., Champeme, M.H., Gest, J., and Callahan, R. 1986. Genetic alteration of the c-myc protooncogene (MYC) in human primary breast carcinomas. Proc. Nat1. Acad. Sci. 83: 4834-4838.

Ethier, S.P. 1996. Human breast cancer cell lines as models of growth regulation and disease progression. I. Mammary Gland Biol. \& Neoplasia 1: 111-121.

Facchini, L.M. and Penn, L.Z. 1998. The molecular role of Myc in growth and transformation: Recent discoveries lead to new insights. FASEB J. 12: 633-651.

Feuer, G., Stewart, S.A., Baird, S.M., Lee, F., Feuer, R., and Chen, I.S. 1995. Potential role of natural killer cells in controlling tumorigenesis by human T-cell leukemia viruses. J. Virol. 69: 1328-1333.

Fidler, I.J., Naito, S., and Pathak, S. 1990. Orthotopic implantation is essential for the selection, growth and metastasis of human renal cell cancer in nude mice. Cancer Metastasis Rev. 9: 149-165.

Finney, R.E. and Bishop, J.M. 1993. Predisposition to neoplastic transformation caused by gene replacement of H-ras1. Science 260: 1524-1527.

Foster, S.A. and Galloway, D.A. 1996. Human papillomavirus type $16 \mathrm{E} 7$ alleviates a proliferation block in early passage human mammary epithelial cells. Oncogene 12: 1773-1779.

Foster, S.A., Wong, D.J., Barrett, M.T., and Galloway, D.A. 1998. Inactivation of p16 in human mammary epithelial cells by CpG island methylation. Mol. Cell. Biol. 18: 1793 1801.

Gillett, C., Fantl, V., Smith, R., Fisher, C., Bartek, J., Dickson, C., Barnes, D., and Peters, G. 1994. Amplification and overexpression of cyclin D1 in breast cancer detected by immunohistochemical staining. Cancer Res. 54: 1812-1817.

Hahn, W.C., Counter, C.M., Lundberg, A.S., Beijersbergen, R.L., Brooks, M.W., and Weinberg, R.A. 1999. Creation of human tumour cells with defined genetic elements. Nature 400: 464-468.

Harper, J.R., Roop, D.R., and Yuspa, S.H. 1986. Transfection of the EJ rasHa gene into keratinocytes derived from carcinogen-induced mouse papillomas causes malignant progression. Mol. Cell. Biol. 6: 3144-3149.

Hovey, R.C., McFadden, T.B., and Akers, R.M. 1999. Regulation of mammary gland growth and morphogenesis by the mammary fat pad: A species comparison. I. Mammary Gland Biol. Neoplasia 4: 53-68.

Jat, P.S., Cepko, C.L., Mulligan, R.C., and Sharp, P.A. 1986. Recombinant retroviruses encoding simian virus 40 large $\mathrm{T}$ antigen and. Mol. Cell. Biol. 6: 1204-1217.

Jiang, X.R., Jimenez, G., Change, E., Frolkis, M., Kusler, B., Sage, M., Beeche, M., Bodnar, A.G., Wahl, G.M., Tlsty, T.D., and Chiu, C.P. 1999. Telomerase expression in human somatic cells does not induce changes associated with a transformed phenotype. Nat. Genet. 21: 111-114.

Kiyono, T., Foster, S.A., Koop, J.I., McDougall, J.K., Galloway, D.A., and Klingelhutz, A.J. 1998. Both Rb/p16INK4a inactivation and telomerase activity are required to immortalize human epithelial cells. Nature 396: $84-88$.

Kleinman, H.K., McGarvey, M.L., Hassell, J.R., Star, V.L., Cannon, F.B., Laurie, G.W., and Martin, G.R. 1986. Basement membrane complexes with biological activity. Biochemistry 25: 312-318.

Kytola, S., Rummukainen, J., Nordgren, A., Karhu, R., Farnebo, F., Isola, J., and Larsson, C. 2000. Chromosomal alterations 
in 15 breast cancer cell lines by comparative genomic hybridization and spectral karyotyping. Genes Chromosomes Cancer 28: 308-317.

Land, H., Parada, L.F., and Weinberg, R.A. 1983. Tumorigenic conversion of primary embryo fibroblasts requires at least two cooperating oncogenes. Nature 304: 596-602.

Lapidus, R.G., Nass, S.J., and Davidson, N.E. 1998. The loss of estrogen and progesterone receptor gene expression in human breast. J. Mammary Gland Biol. Neoplasia 3: 85-94.

Miller, F.R., Medina, D., and Heppner, G.H. 1981. Preferential growth of mammary tumors in intact mammary fatpads. Cancer Res. 41: 3863-3867.

Mombaerts, P., Iacomini, J., Johnson, R.S., Herrup, K., Tonegawa, S., and Papaioannou, V.E. 1992. RAG-1-deficient mice have no mature B and T lymphocytes. Cell 68: 869877.

Morales, C.P., Holt, S.E., Ouellette, M., Kaur, K.J., Yan, Y., Wilson, K.S., White, M.A., Wright, W.E., and Shay, J.W. 1999. Absence of cancer-associated changes in human fibroblasts immortalized with telomerase. Nat. Genet. 21: 115-118.

Morgenstern, J.P. and Land, H. 1990. Advanced mammalian gene transfer: High titre retroviral vectors with multiple drug selection markers and a complementary helper-free packaging cell line. Nucleic Acids Res. 18: 3587-3596.

Noel, A., De Pauw-Gillet, M.C., Purnell, G., Nusgens, B., Lapiere, C.M., and Foidart, J.M. 1993. Enhancement of tumorigenicity of human breast adenocarcinoma cells in nude mice by matrigel and fibroblasts. Br. J. Cancer 68: 909-915.

Olumi, A.F., Grossfeld, G.D., Hayward, S.W., Carroll, P.R., Tlsty, T.D., and Cunha, G.R. 1999. Carcinoma-associated fibroblasts direct tumor progression of initiated human prostatic epithelium. Cancer Res. 59: 5002-5011.

Ozbun, M.A. and Butel, J.S. 1995. Tumor suppressor p53 mutations and breast cancer: A critical analysis. Adv. Cancer Res. 66: 71-141.

Price, J.E., Polyzos, A., Zhang, R.D., and Daniels, L.M. 1990. Tumorigenicity and metastasis of human breast carcinoma cell lines in nude mice. Cancer Res. 50: 717-721.

Rodriguez-Puebla, M.L., LaCava, M., Bolontrade, M.F., Russell, J., and Conti, C.J. 1999. Increased expression of mutated Haras during premalignant progression in SENCAR mouse skin. Mol. Carcinog. 26: 150-156.

Ronnov-Jessen, L., Petersen, O.W., and Bissell, M.J. 1996. Cellular changes involved in conversion of normal to malignant breast: importance of the stromal reaction. Physiol. Rev. 76: 69-125.

Rowley, D.R. 1998. What might a stromal response mean to prostate cancer progression? Cancer Metastasis Rev. 17: 411-419.

Ruley, H.E. 1983. Adenovirus early region 1A enables viral and cellular transforming genes to transform primary cells in culture. Nature 304: 602-606.

Schrock, E., du Manoir, S., Veldman, T., Schoell, B., Weinberg, J., Ferguson, M.A., Ning, Y., Ledbatter, D.H., Bar-Am, I., Soenksen, D., et al. 1996. Multicolor spectral karyotyping of human chromosomes. Science 273: 494-497.

Serrano, M., Lin, A.W., McCurrach, M.E., Beach, D., and Lowe, S.W. 1997. Oncogenic ras provokes premature cell senescence associated with accumulation of p53 and p16INK4a. Cell 88: 593-602.

Shay, J.W., Wright, W.E., Brasiskyte, D., and Van der Haegen, B.A. 1993. E6 of human papillomavirus type 16 can overcome the M1 stage of immortalization in human mammary epithelial cells but not in human fibroblasts. Oncogene 8: 1407-1413.
Shpitz, B., Zimlichman, S., Zemer, R., Bomstein, Y., Zehavi, T., Liverant, S., Bernehim, J., Kaufman, Z., Klein, E., Shapira, Y., et al. 1999. Telomerase activity in ductal carcinoma in situ of the breast. Breast Cancer Res. Treat. 58: 65-69.

Slamon, D.J., Godolphin, W., Jones, L.A., Holt, J.A., Wong, S.G., Keith, D.E., Levin, W.J., Stuart, S.G., Udove, J., Ullrich, A., et al. 1989. Studies of the HER-2/neu proto-oncogene in human breast and ovarian cancer. Science 244: 707-712.

Stampfer, M.R. 1985. Isolation and growth of human mammary epithelial cells. J. Tissue Culture Methods 9: 107-115.

Tirkkonen, M., Tanner, M., Karhu, R., Kallioniemi, A., Isola, J., and Kallioniemi, O.P. 1998. Molecular cytogenetics of primary breast cancer by CGH. Genes Chromosomes Cancer 21: $177-184$.

Varley, J.M., Armour, J., Swallow, J.E., Jeffreys, A.J., Ponder, B.A., T'Ang, A., Fung, Y.K., Brammar, W.J., and Walker, R.A. 1989. The retinoblastoma gene is frequently altered leading to loss of expression in primary breast tumours. Oncogene 4: 725-729.

Wang, J., Hannon, G.J., and Beach, D.H. 2000. Risky immortalization by telomerase. Nature 405: 755-756.

Zimonjic, D.B. and Popescu, N.C. 1994. An improved procedure for chromosome preparations from solid tumors. Cancer Genet. Cytogenet. 72: 161.

Zimonjic, D.B., Rezanka, L., DiPaolo, J.A., and Popescu, N.C. 1995. Refined localization of the erbB-3 proto-oncogene by direct visualization of FISH signals on LUT-inverted and contrast-enhanced digital images of DAPI-banded chromosomes. Cancer Genet. Cytogenet. 80: 100-102.

Zimonjic, D.B., Keck-Waggoner, C.L., Yuan, B.Z., Kraus, M.H., and Popescu, N.C. 2000. Profile of genetic alterations and tumorigenicity of human breast cancer cells. Int. J. Oncol. 16: $221-230$. 


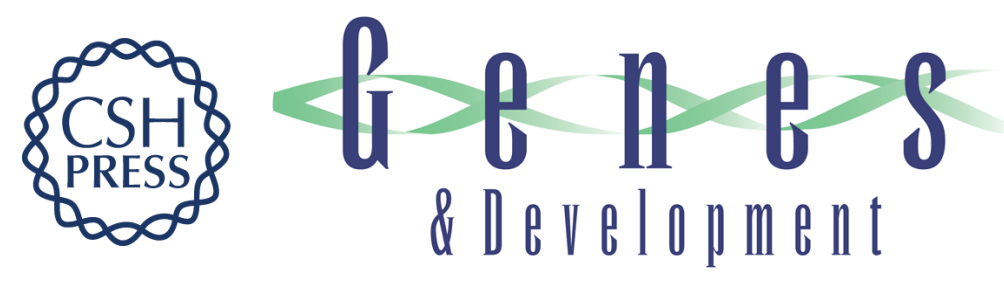

\section{Human breast cancer cells generated by oncogenic transformation of primary mammary epithelial cells}

Brian Elenbaas, Lisa Spirio, Frederick Koerner, et al.

Genes Dev. 2001, 15:

Access the most recent version at doi:10.1101/gad.828901

References This article cites 51 articles, 16 of which can be accessed free at: http://genesdev.cshlp.org/content/15/1/50.full.html\#ref-list-1

License

Email Alerting

Receive free email alerts when new articles cite this article - sign up in the box at the top Service right corner of the article or click here.

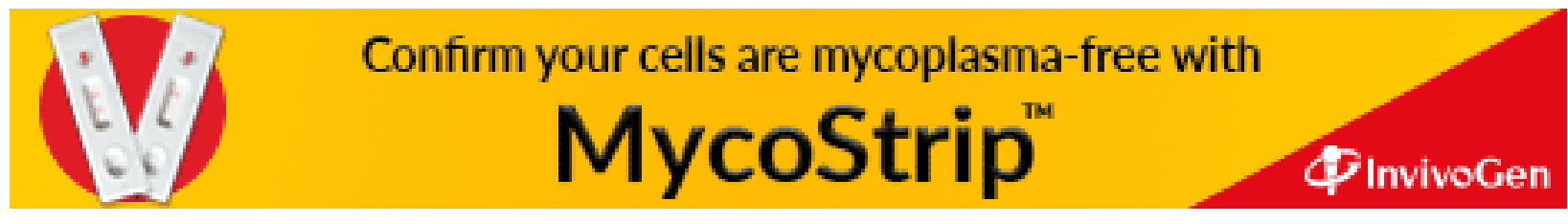

